\title{
Poldip2/Nox4 Mediates Lipopolysaccharide-Induced Oxidative Stress and Inflammation in Human Lung Epithelial Cells
}

\author{
Yueguo Wang $\mathbb{D}^{1,2}$ Zhenxing Ding $\mathbb{D}^{1},{ }^{1}$ Youhui Tu $\mathbb{D}^{1},{ }^{1} \mathrm{Xu} \mathrm{Wu} \mathbb{D}^{1},{ }^{1}$ Wenying Zhang ${ }^{1},{ }^{1}$

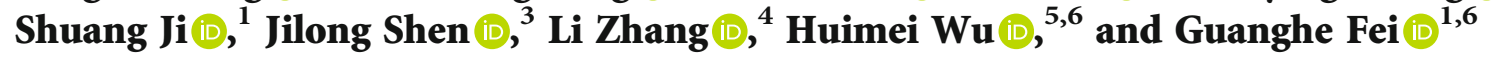 \\ ${ }^{1}$ Department of Respiratory and Critical Care Medicine, The First Affiliated Hospital of Anhui Medical University, Hefei, \\ 230022 Anhui, China \\ ${ }^{2}$ Department of Emergency Medicine, The First Affiliated Hospital of USTC, Division of Life Sciences and Medicine, University of \\ Science and Technology of China, Hefei, 230001 Anhui, China \\ ${ }^{3}$ Department of Pathogen Biology and Provincial Laboratories of Pathogen Biology and Zoonoses, Anhui Medical University, Hefei, \\ 230032 Anhui, China \\ ${ }^{4}$ The Center for Scientific Research, The First Affiliated Hospital of Anhui Medical University, Hefei, 230022 Anhui, China \\ ${ }^{5}$ Anhui Geriatric Institute, Department of Geriatric Respiratory and Critical Care, The First Affiliated Hospital of Anhui \\ Medical University, Hefei, 230022 Anhui, China \\ ${ }^{6}$ Key Laboratory of Respiratory Disease Research and Medical Transformation of Anhui Province, The First Affiliated Hospital of \\ Anhui Medical University, Hefei, 230022 Anhui, China
}

Correspondence should be addressed to Huimei Wu; wuhm@ahmu.edu.cn and Guanghe Fei; guanghefei@126.com

Received 2 December 2020; Revised 10 November 2021; Accepted 30 December 2021; Published 30 January 2022

Academic Editor: Sandra Helena Penha Oliveira

Copyright (C) 2022 Yueguo Wang et al. This is an open access article distributed under the Creative Commons Attribution License, which permits unrestricted use, distribution, and reproduction in any medium, provided the original work is properly cited.

NADPH oxidase 4 (Nox4) is an important source of reactive oxygen species (ROS) production, and its expression is increased in lipopolysaccharide- (LPS-) stimulated lung epithelial cells. Polymerase $\delta$-interacting protein 2 (Poldip2) has been proved to bind Nox 4 and participates in oxidative stress and inflammation. However, the role of Poldip2/Nox4 in LPS-induced oxidative stress and inflammation in lung epithelial cells remains unclear. Cell viability was measured via MTT assays. The expression of Poldip2, Nox4, heme oxygenase-1 (HO-1), cyclooxygenase-2 (COX-2), AKT, and p-AKT was detected by Western blotting and/or immunofluorescence. Poldip2 and Nox4 interaction was analyzed via coimmunoprecipitation (Co-IP) assay. NADPH enzymatic activity and production of ROS, prostaglandin E2 (PGE2), tumor necrosis factor- $\alpha$ (TNF- $\alpha$ ), and interleukin-1 $\beta$ (IL-1 $\beta$ ) were assessed simultaneously. The small interfering RNA (siRNA) or plasmid targeting Nox4 was used to downregulate or upregulate Nox4, and the lentiviral vector encoding Poldip2 was used to downregulate or upregulate Poldip2. The present study demonstrated that LPS stimulation significantly increased the protein levels of Poldip 2 and Nox4 and proved that Poldip2 interacted with Nox4 proved by Co-IP. Importantly, Poldip2 acted as an upstream regulator of Nox4. The increased expression of Nox 4 and COX-2; NADPH enzymatic activity; production of ROS, PGE2, TNF- $\alpha$, and IL-1 $\beta$; and decreased HO-1 expression were significantly suppressed by lentiviral Poldip2 shRNA downregulation but were increased by lentiviral upregulation of Poldip2. Furthermore, inhibiting of PI3K-AKT signaling notably attenuated LPS-induced Poldip2/ Nox4 activation. Our study demonstrated that Poldip2 mediates LPS-induced oxidative stress and inflammation via interaction with Nox4 and was regulated by the PI3K-AKT signaling. Targeting Poldip2 could be a beneficial therapeutic strategy for the treatment of ALI.

\section{Introduction}

Lipopolysaccharide (LPS), a major constituent of the cell walls of Gram-negative bacteria, plays a vital role in the development and progression of acute lung injury (ALI) [1]. It can initiate production of biologically active molecules from a variety of cells $[2,3]$, including inflammatory cytokines and reactive oxygen species (ROS). Mounting evidence 
suggests that oxidative stress is associated with the progression of ALI $[4,5]$. Excessive ROS production overwhelms antioxidant defenses thereby increasing the inflammatory processes and ultimately leading to tissue injury, especially lung epithelial cell damage [6]. The NADPH oxidase family of enzymes is thought to be a major source of ROS under various pathological conditions [7], which consists of seven isozymes, including Nox1-Nox5, DUOX1, and DUOX2 [8]. Importantly, NADPH oxidase 4 (Nox4) is widely expressed in human lung epithelial cells [9]. Previously, studies showed that LPS markedly increased NADPH oxidase activation, including Nox4, and intracellular ROS production in human lung epithelial cells [10] and the mouse preclinical model of ALI [11]. These observations indicate that Nox4-mediated oxidative stress and inflammation may be enhanced by LPS stimulation and implicated in LPSinduced ALI. However, the mechanism of the activation of Nox4 and Nox4-mediating effects during LPS stimulation is not completely understood.

Additionally, polymerase $\delta$-interacting protein 2 (Poldip2) (also known as polymerase delta-interacting protein 38 (PDIP38) and mitogenin-1) is a multifunctional protein initially identified as a binding partner of the DNA polymerase $\delta$ p50 subunit and proliferating cell nuclear antigen (PCNA) [12]. Poldip2 is widely expressed in human primary pulmonary microvascular endothelial cells (HPMECs) [13] and lung epithelial cells [14]. In addition to its role in DNA replication and damage repair [12], Poldip2 served as a protein chaperone and is involved in mitochondrial function and morphology $[15,16]$, extracellular matrix synthesis [17], and degradation [18], as well as cell cycle progression [19]. Previously, a study has demonstrated that Poldip2 binds Nox4 in a yeast two-hybrid assay [20], it also increases Nox4 enzymatic activity, and positively regulates basal ROS production in vascular smooth muscle cells and HPMECs $[13,20]$. In addition, a recent study demonstrated that reduced Poldip2 protects against LPS induced-acute respiratory distress syndrome (ARDS) through suppressing mitochondrial ROS production in a mouse model [13]. Collectively, Poldip2 is a key protein in regulating the progression of ALI but how Poldip2 regulates the expression of Nox4 and enzymatic activity of NADPH oxidases in response to LPS in lung epithelial cells deserves further research.

The aim of this study was at determining the potential specific role of Poldip2, identifying how it regulates the expression of Nox4, enzymatic activity of NADPH oxidases, and Nox4 downstream effects on human lung epithelial cells and to elucidate the potential molecular mechanisms further.

\section{Materials and Methods}

2.1. Reagents and Materials. DMEM medium and 1640 medium were purchased from HyClone (HyClone, USA), and fetal bovine serum was purchased from Gibco (Gibco, USA). LPS and LY294002 were purchased from Sigma (Sigma-Aldrich, USA). RIPA lysis buffer, DAPI, rabbit IgG, puromycin, and FITC-conjugated secondary antibody were purchased from Beyotime (Beyotime, China). Primary anti- bodies of Poldip2, HO-1, COX-2, AKT, p-AKT, and $\beta$-actin were purchased from Abcam (Abcam, UK). Primary antibodies of Nox 4 were purchased from Novus (Novus, USA).

2.2. Cell Culture. The human lung adenocarcinoma cell line A549 and human bronchial epithelial cell line Beas-2B were obtained from the Cell Bank of Chinese Academy of Sciences (Shanghai, China). Cells were cultured at $37^{\circ} \mathrm{C}$ in a humidified atmosphere with $5 \% \mathrm{CO}_{2}$ in DMEM medium or 1640 medium supplemented with $10 \%$ fetal bovine serum, $100 \mathrm{U} / \mathrm{mL}$ penicillin, and $100 \mathrm{mg} / \mathrm{mL}$ streptomycin, respectively.

2.3. Cell Viability Assay. The cell viability was measured by MTT assay. Cells were treated with different doses of LPS $(0,2.5,5,10,15,20$, and $40 \mu \mathrm{g} / \mathrm{mL}$ for A549 cells and 0 , $0.25,0.5,1,2,5$, and $10 \mu \mathrm{g} / \mathrm{mL}$ for Beas-2B cells) for $24 \mathrm{~h}$, $10 \mu \mathrm{L}$ of MTT solution $(5 \mathrm{mg} / \mathrm{mL})$ was added to each well for culturing at $37^{\circ} \mathrm{C}$ for $4 \mathrm{~h}$, and $100 \mu \mathrm{L}$ of DMSO was added to solubilize formazan crystals. The absorbance at a $570 \mathrm{~nm}$ wavelength was measured by a microplate reader (BioTek, USA). The results were expressed as the mean percentage of absorbance in the treatment group versus the control group.

2.4. Western Blotting. Cell proteins were extracted using RIPA lysis buffer. Proteins were electrophoresed on $10 \%$ SDS-PAGE gel and electrotransferred to polyvinylidene difluoride (PVDF) membranes. The membranes were blocked using 5\% skimmed milk at room temperature for $2 \mathrm{~h}$ and incubated with primary antibodies for $12 \mathrm{~h}$ at $4^{\circ} \mathrm{C}$. Horseradish peroxidase-conjugated secondary antibody was added at $37^{\circ} \mathrm{C}$ for $1 \mathrm{~h}$. In this study, primary antibodies of Poldip2 (1:1000), Nox4 (1:1000), HO-1 (1:1000), COX$2(1: 1000)$, AKT $(1: 1000)$, and p-AKT $(1: 1000)$ were used and $\beta$-actin $(1: 5000)$ worked as an endogenous control. The bands were detected by enhanced a chemiluminescence (ECL) detection kit (Thermo Fisher Scientific, Barrington, IL, USA). Densitometry for all proteins was normalized against control.

2.5. NADPH Enzymatic Activity Assay. NADPH enzymatic activity was measured using a commercially available kit (Genmed Scientifics, Shanghai, China) according to the manufacturer's protocols. Briefly, the supernatant of cell lysates was incubated with oxidized cytochrome $\mathrm{c}$ in a quartz cuvette at $30^{\circ} \mathrm{C}$ for $3 \mathrm{~min}$ and then mixed with the Nox substrate (NADPH) and incubated for $15 \mathrm{~min}$. The change of absorbance at $340 \mathrm{~nm}$ was monitored by a spectrophotometer. NADPH enzymatic activity was estimated by calculating cytochrome $\mathrm{c}$ reduction per min.

2.6. Coimmunoprecipitation Assay. For the endogenous interaction assay, cells were cultured in a $10 \mathrm{~cm}$ culture dish with $60 \%$ confluence and then treated with LPS for $12 \mathrm{~h}$. After lysis and collection of cells, equal amounts of lysates were incubated overnight at $4^{\circ} \mathrm{C}$ with $3 \mu \mathrm{g}$ of the primary antibodies of Poldip2 or normal rabbit IgG (isotype controls) and protein G Mag Sepharose (Thermo Fisher Scientific, Waltham, MA, USA). The proteins bound to 
antibodies were pulled down by protein $G$ beads and subjected to immunoblotting analysis.

2.7. Intracellular ROS Assay. Production of intracellular ROS was measured with dichlorodihydrofluorescein diacetate (DCFH-DA) (Beyotime, China) per the manufacturer's instructions. Briefly, the cells were treated with trypsin, incubated with $10 \mu \mathrm{mol} / \mathrm{L}$ DCFH-DA at $37^{\circ} \mathrm{C}$ for $20 \mathrm{~min}$, and washed with PBS 3 times. Then, cells were rinsed with DMEM and analyzed by flow cytometry (BD Biosciences, Franklin Lakes, NJ).

2.8. Determination of PGE2, TNF- $\alpha$, and $I L-1 \beta$. Enzymelinked immunosorbent assay (ELISA) was used to measure the levels of PGE2, TNF- $\alpha$ and IL- $1 \beta$ in culture supernatants according to the manufacturer's instructions. The levels of TNF- $\alpha$ and IL- $1 \beta$ were determined using ELISA kits (absin, China), and PGE2 was determined using ELISA kits (CUSABIO BIOTECH, China).

2.9. siRNA-Mediated Downregulation of Nox4. The siRNA targeting Nox4 and negative control siRNA were obtained from the Hanbio Biotechnology Co. Ltd. (Shanghai, China). Cells were seeded and cultured in 6-well plates for $24 \mathrm{~h}$ with 30-50\% confluence. Cells were transfected with siRNA using lipofectamine 2000 (Invitrogen, Carlsbad, CA, USA) in accordance with the manufacturer's protocols. Nox4 siRNAtransfected cells and negative control siRNA-transfected cells were defined as siNox 4 and siCont. After $72 \mathrm{~h}$, the expression of Nox 4 and transfection efficiency were detected by Western blotting. The siNox4 sequences are listed as follows: sense: $5^{\prime}$ GCAAUAAGCCAGUCACCAUTT- $3^{\prime}$ and antisense: $5^{\prime}$ AUGGUGACUGGCUUAUUGCTT-3'.

2.10. Plasmid-Mediated Upregulation of Nox4. The Nox4 plasmid and empty vector were constructed by the Hanbio Biotechnology Co. Ltd. (Shanghai, China). Cells were seeded and cultured in 6-well plates for $24 \mathrm{~h}$ with $30-50 \%$ confluence. Cells were transfected with Nox4 plasmid or the empty vector by lipofectamine 2000 following the manufacturer's instructions. After $72 \mathrm{~h}$, the expression of Nox 4 and transfection efficiency were detected by Western blotting. The primer sequences are listed as follows: forward: $5^{\prime}-\mathrm{CAAG}$ CTGTGACCGGCGCCTACGAATTCGCCACCATGGCT GTGTCCTGG-3' and reverse: $5^{\prime}$-ACCCCATCGATGGA CCGGTCGGGATCCGCTGAAAGACTCTTTATTGT-3’.

2.11. Lentivirus-Mediated Downregulation of Poldip2. A lentivirus vector containing Poldip2-specific shRNA or nonspecific shRNA (as a negative control) was constructed from the Hanbio Biotechnology Co. Ltd. (Shanghai, China). Cells were seeded and cultured in 6-well plates for $24 \mathrm{~h}$ with $30-$ $50 \%$ confluence. Cells were transfected with a lentivirus vector and incubated for $24 \mathrm{~h}$, and the supernatants were exchanged with fresh culture medium and cultured for $72 \mathrm{~h}$. Stable-transfected cells were isolated using $2 \mu \mathrm{g} / \mathrm{mL}$ of puromycin to screen for puromycin resistance gene production. Poldip 2 shRNA-transfected cells and negative control shRNA-transfected cells were defined as shPoldip2 and
shCont. After $72 \mathrm{~h}$, the expression of Poldip2 and transfection efficiency were evaluated by Western blotting. The shPoldip2 sequences are listed as follows: top strand: $5^{\prime}$ GATCCGGCGCTACTGTATCCGTTTGGAGAATTCAAG AGATTCTCCAAACGGATACAGTAGCGCCTTTTTTG-

$3^{\prime}$ and bottom strand: 5'-AATTCAAAAAAGGCGCTAC TGTATCCGTTTGGAGAATCTCTTGAATTCTCCAAA CGGATACAGTAGCGCCG-3' .

2.12. Lentivirus-Mediated Upregulation of Poldip2. Lentivirus upregulating Poldip2 particles and lentivirus upregulating control particles were constructed from the Hanbio Biotechnology Co. Ltd. (Shanghai, China). Cells were seeded and cultured in 6-well plates for $24 \mathrm{~h}$ to obtain $30-50 \%$ confluence. The lentiviral particles were then added to the wells at a multiplicity of infection (MOI) value of 50:1 and cultured with cells. After $24 \mathrm{~h}$, the culture medium was replaced with the fresh complete medium, added $2 \mu \mathrm{g} / \mathrm{mL}$ of puromycin, and cultured for an additional $72 \mathrm{~h}$. The puromycin-resistant cells were then isolated. Poldip2upregulated cells and upregulating control cells were defined as LvPoldip2 and LvCont. The expression of Poldip2 and transfection efficiency were evaluated by Western blotting. The primer sequences are listed as follows: forward: $5^{\prime}$ AGAGGATCTATTTCCGGTGAATTCGCCACCATGGCA GCCTGTACAGCCC-3' and reverse: $5^{\prime}$-GTCACTTAAGC TTGGTACCGAGGATCCCAGTGAAGGCCTGAGGGTG GT-3'.

2.13. Immunofluorescence Analysis. Cells were fixed in $4 \%$ paraformaldehyde for $15 \mathrm{~min}$ and blocked with $5 \%$ goat serum for $2 \mathrm{~h}$ at room temperature and then incubated with primary antibodies of Poldip 2 and Nox 4 at $4^{\circ} \mathrm{C}$.After overnight incubation, cells were washed with PBS and incubated with a fluorescein isothiocyanate- (FITC-) conjugated secondary antibody. Nuclei were stained with DAPI. Cells were viewed with an inverted LSM880 confocal laser-scanning microscope (Carl Zeiss, Jena, Germany) with blue and green channels.

2.14. Statistical Analysis. All data analyses were performed using SPSS 23.0 software (SPSS Inc., Chicago, IL, USA). The results are expressed as mean \pm SD. Comparisons among groups were determined using Student's $t$-test or one-way ANOVA followed by Tukey's post hoc test. $P<0.05$ was considered statistically significant.

\section{Results}

3.1. LPS Increased the Protein Expression of Poldip2 and Nox4 in Lung Epithelial Cells in a Dose-/Time-Dependent Manner. We first checked the effect of LPS stimulation on the viability of A549 and Beas-2B cells. Cells were exposed to the different doses of LPS $(0-40 \mu \mathrm{g} / \mathrm{mL}$ for A549 cells and $0-10 \mu \mathrm{g} / \mathrm{mL}$ for Beas-2B cells) for $24 \mathrm{~h}$ in a serum-free medium, and cell viability was assessed by the MTT reduction assay. As LPS doses are rising, the cell viability had decreased significantly. As shown in Figures 1(a) and 1(b), for A549 cells, LPS at $40 \mu \mathrm{g} / \mathrm{mL}$ significantly decreased 

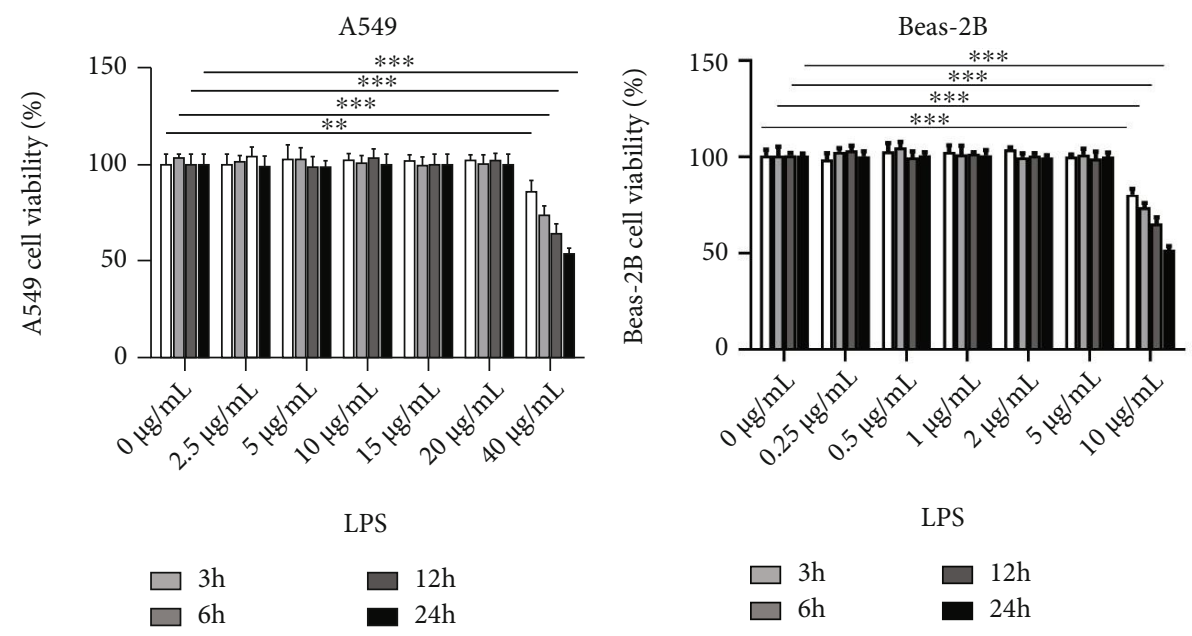

(a)

(b)
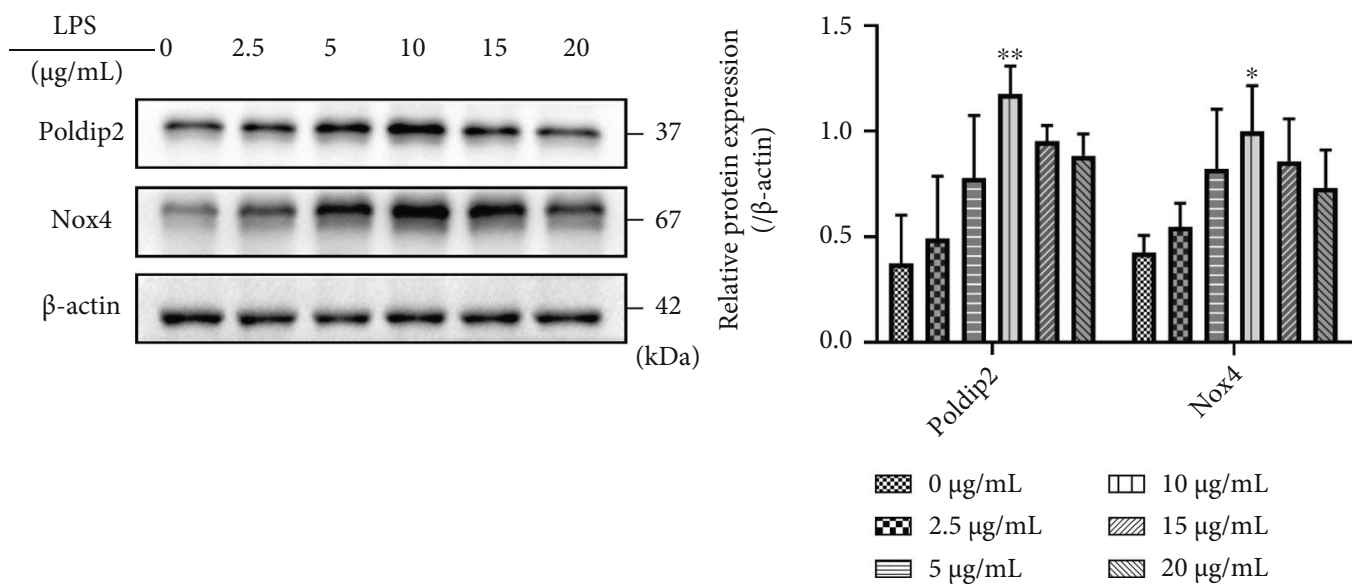

(c)
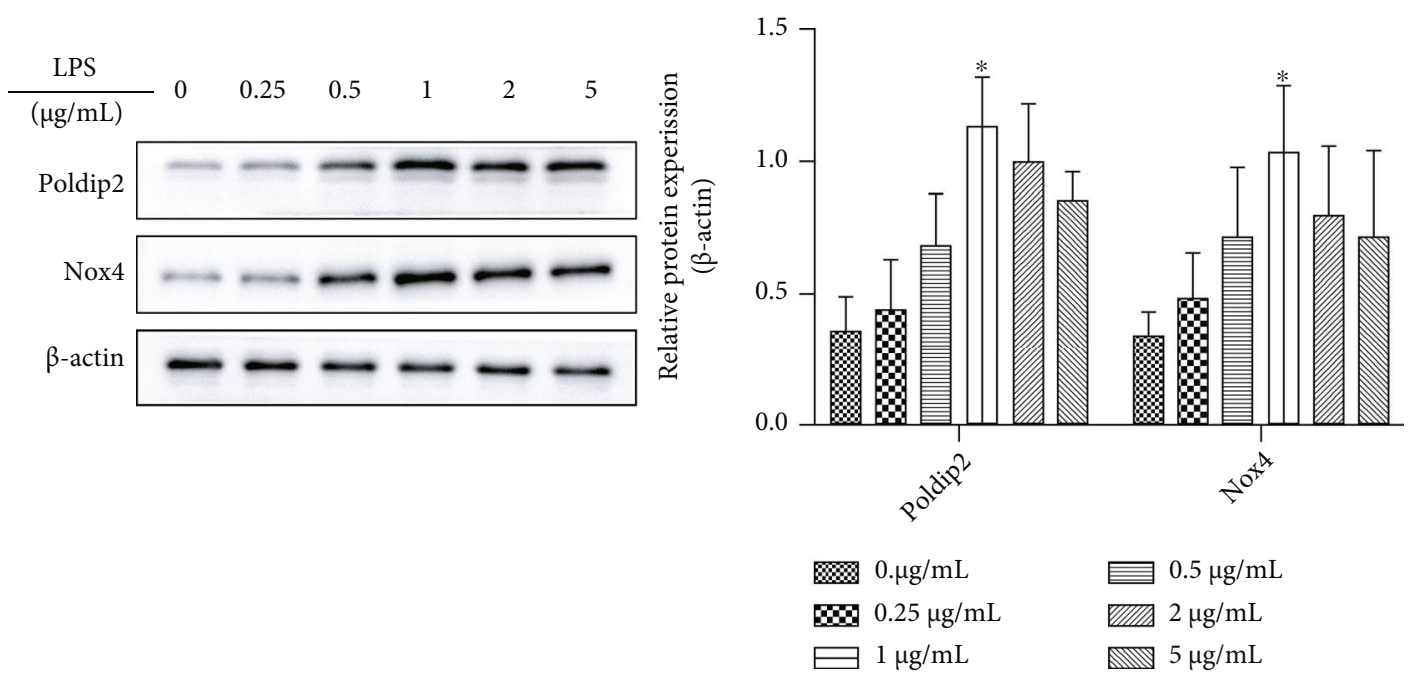

(d)

Figure 1: Continued. 

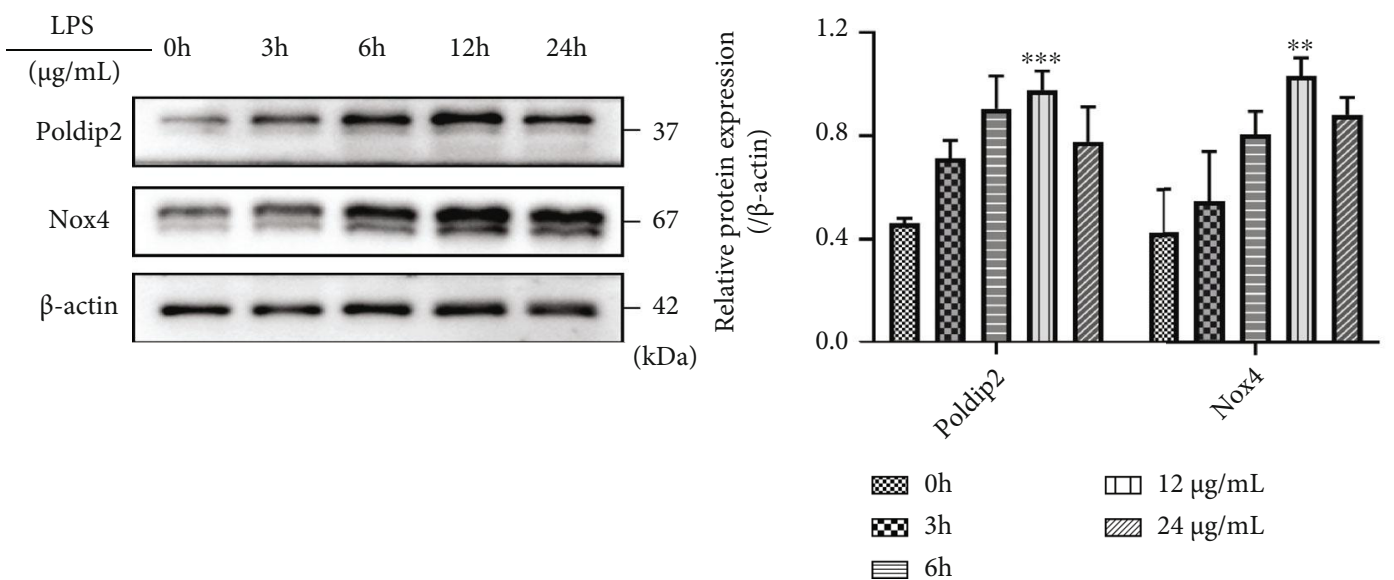

(e)
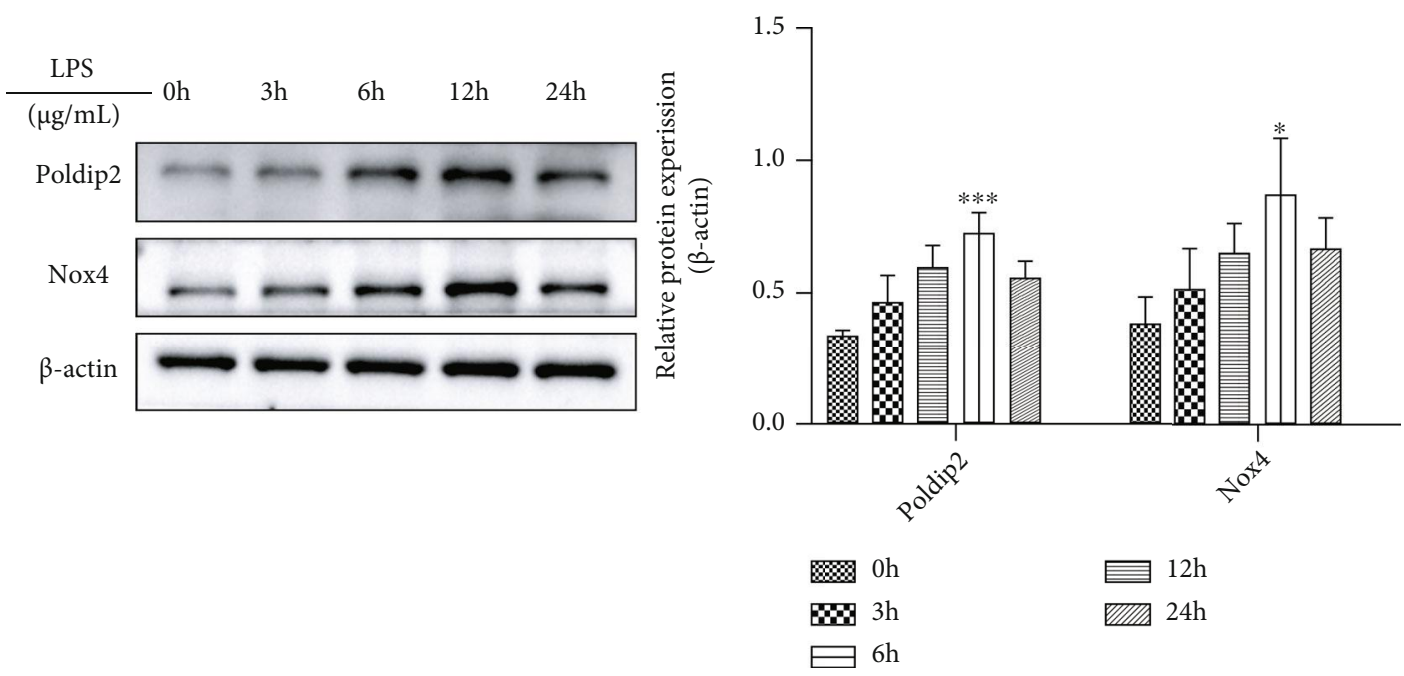

(f)

Figure 1: Poldip2 and Nox4 were upregulated in response to LPS in a dose/time-dependent manner in human lung epithelial cells. (a, b) A549 and Beas-2B cells were treated with the different doses of LPS ( $0-40 \mu \mathrm{g} / \mathrm{mL}$ for A549 cells, $0-10 \mu \mathrm{g} / \mathrm{mL}$ for Beas-2B cells) for $24 \mathrm{~h}$, and the cell viability was analyzed by MTT assay. (c, d) Confluent cells were treated with different doses of LPS (0-20 $\mu \mathrm{g} / \mathrm{mL}$ for A549 cells and $0-5 \mu \mathrm{g} / \mathrm{mL}$ for Beas-2B cells) for $12 \mathrm{~h}$, and the protein levels of Poldip 2 and Nox 4 were detected by Western blotting and quantitatively analyzed. (e, f) Confluent cells were treated with LPS $(10 \mu \mathrm{g} / \mathrm{mL}$ for A549 cells and $1 \mu \mathrm{g} / \mathrm{mL}$ for Beas-2B cells) for the different times $(0-24 \mathrm{~h})$, and the protein levels of Poldip2 and Nox4 were detected by Western blotting and quantitatively analyzed. Bars are mean \pm standard deviation(SD) of 3 independent experiments. ${ }^{* * *} P<0.001$ vs. $0 \mu \mathrm{g} / \mathrm{mL}$ or $0 \mathrm{~h},{ }^{* *} P<0.01 \mathrm{vs}$. $0 \mu \mathrm{g} / \mathrm{mL}$ or $0 \mathrm{~h}$, and ${ }^{*} P<0.05$ vs. $0 \mu \mathrm{g} / \mathrm{mL}$ or $0 \mathrm{~h}$.

cellular MTT reduction, but at $20 \mu \mathrm{g} / \mathrm{mL}$ or less, it showed no toxicity. For Beas-2B cells, LPS at $10 \mu \mathrm{g} / \mathrm{mL}$ notably decreased cellular MTT reduction, but at $5 \mu \mathrm{g} / \mathrm{mL}$ or less, it showed no toxicity. Therefore, we chose to treat the cells with different doses of LPS $(0-20 \mu \mathrm{g} / \mathrm{mL}$ for A549 cells and $0-5 \mu \mathrm{g} / \mathrm{mL}$ for Beas-2B cells) for $12 \mathrm{~h}$ in the following experiments.

Next, our study determined whether LPS affects the expression of Poldip2 and Nox4 and cells were exposed to different doses of LPS $(0-20 \mu \mathrm{g} / \mathrm{mL}$ for A549 cells and 0$5 \mu \mathrm{g} / \mathrm{mL}$ for Beas-2B cells) for $12 \mathrm{~h}$ and protein expression was detected by Western blotting. In the two epithelial cells, the baseline expression of Poldip2 and Nox4 was at $0 \mu \mathrm{g} / \mathrm{mL}$ and peaked at $10 \mu \mathrm{g} / \mathrm{mL}$ and $1 \mu \mathrm{g} / \mathrm{mL}$, respectively (Figures 1(c) and 1(d)). Then, the protein levels of Poldip2 and Nox4 were monitored at the different times $(0-24 \mathrm{~h})$ after LPS treatment with $10 \mu \mathrm{g} / \mathrm{mL}$ and $1 \mu \mathrm{g} / \mathrm{mL}$, respectively. The result showed that LPS significantly increased the expression of Poldip2 and Nox4 in a dose-dependent manner and the maximum levels were at $10 \mu \mathrm{g} / \mathrm{mL}$ and $1 \mu \mathrm{g} / \mathrm{mL}$, respectively (Figures $1(\mathrm{e})$ and $1(\mathrm{f})$ ). Taken together, LPS induced Poldip2 and Nox4 expression in a dose-/timedependent manner in A549 and Beas-2B cells.

\section{Poldip2 Immunoprecipitated with Nox4 in Response to LPS}

Coimmunoprecipitation assay was used to confirm the interaction between Poldip2 and Nox4 during LPS stimulation. Using an antibody specific to Nox4, we observed that 


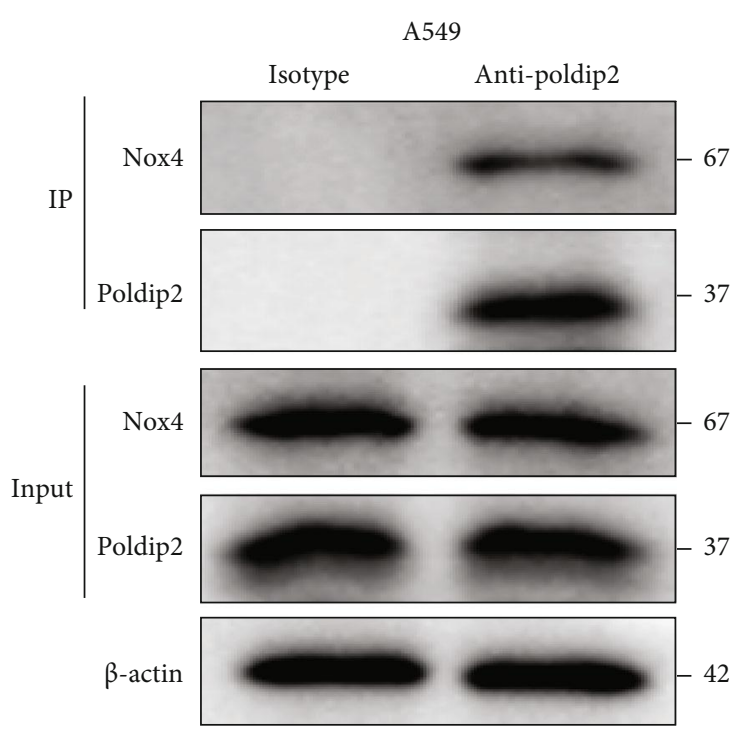

$(\mathrm{kDa})$

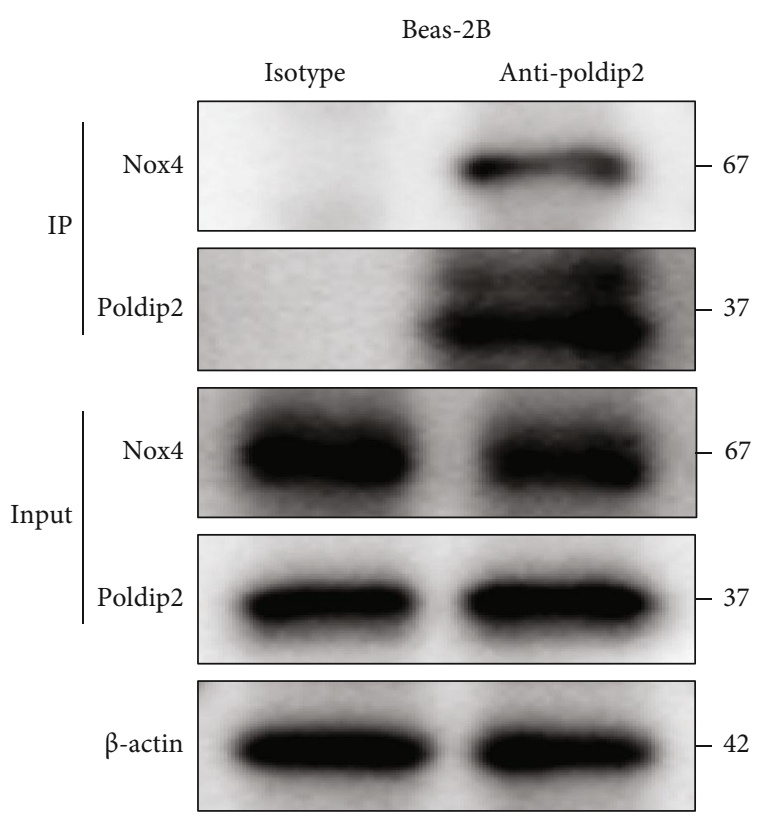

(b)

FIgure 2: Poldip2 interacted with Nox4 induced by LPS with coimmunoprecipitation. $(\mathrm{a}, \mathrm{b})$ Confluent cells were treated with LPS (10 $\mu$ g/ $\mathrm{mL}$ for A549 cells and $1 \mu \mathrm{g} / \mathrm{mL}$ for Beas-2B cells) for $12 \mathrm{~h}$. Cell lysates were immunoprecipitated with normal rabbit IgG (isotype controls) or primary rabbit anti-Poldip 2 antibody and immunoblotted with a mouse anti-Nox4 antibody or rabbit anti-Poldip 2 antibody. Lysis buffer (Input) is a positive control in coimmunoprecipitation.

Poldip2 efficiently immunoprecipitated with Nox4 during LPS stimulation. The respective antibodies recognized two protein bands with expected sizes for Poldip2 $(\sim 37 \mathrm{kDa})$ and Nox4 $(\sim 67 \mathrm{kDa})$ in crude lysate-positive controls (input) (Figure 2).

4.1. Downregulation of Nox4 Suppressed LPS-Induced Oxidative Stress and Inflammation But Had No Effects on Poldip2 Expression. To further investigate the effect of Nox4 downregulation on LPS-induced oxidative stress and inflammation, we performed downregulation of Nox4 in A549 and Beas-2B cells. Cells were transfected with siRNA against Nox4 (siNox4) to downregulate Nox4 expression and compared with the control siRNA vector without construct (siCont) (Figures 3(a) and 3(b)). Transfected cells (siCont and siNox4) were treated with PBS or LPS for $12 \mathrm{~h}$. HO-1 and COX-2, acting as the downstream targets of Nox4, were detected simultaneously, the results showed that downregulation of Nox4 markedly enhanced HO-1 expression but inhibited COX-2 expression (Figures 3(c) and $3(\mathrm{~d})$ ). Moreover, downregulation of Nox4 significantly inhibited the enzymatic activity of NADPH oxidases (Figures 3(h) and $3(\mathrm{j})$ ), as well as ROS generation (Figures 3(k) and 3(l)) under LPS stimulation.

In addition, PGE2, the downstream effector of COX-2, and inflammatory cytokines (TNF- $\alpha$ and IL-1 $\beta$ ) also were analyzed after LPS stimulation. The results showed that downregulation of Nox4 markedly decreased LPS-induced PGE2 production (Figures $3(\mathrm{~m})$ and $3(\mathrm{o})$ ) and the release of TNF- $\alpha$ (Figures 3(n) and 3(p)) and IL-1 $\beta$ (Figures 3(q) and $3(\mathrm{r}))$. However, downregulation of Nox4 had no effects on Poldip2 expression (Figures 3(c) and 3(d)), suggesting that Nox 4 acted as the downstream of Poldip 2 and may mediate the effect of Poldip2. Immunofluorescence analyses (Figures 3(e)-3(g) and 3(i)) were consistent with the results of Western blotting in Figures 3(c) and 3(d).

4.2. Upregulation of Nox4 Increased Oxidative Stress and Inflammation But Had No Effects on Poldip2 Expression. Furthermore, to explore the interdependence and causality of Poldip2 and Nox4, we performed the upregulation of Nox4 via plasmid transfection in the presence or absence of shPoldip2 in A549 and Beas-2B cells. A549 and Beas-2B cells were transfected with Nox4 plasmid or an empty vector for $72 \mathrm{~h}$ and the results showed that transfection of Nox 4 plasmid significantly upregulated the Nox4 protein level comparing with the empty vector (Figures 4(a) and 4(b)). Then, transfected cells (shCont and shPoldip2) were cotransfected with Nox4 plasmid or the empty vector for $72 \mathrm{~h}$. Our data suggested that, compared with cells transfected with the empty vector, Nox4 upregulation markedly attenuated HO-1 expression but enhanced COX-2 expression (Figures 4(c) and 4 (d)), whereas it had no obvious effect on Poldip2. Accordingly, the production of ROS, PGE2, TNF- $\alpha$, and IL- $1 \beta$ was also increased by Nox 4 upregulation (Figures 4(e)-4(l)). Collectively, our study confirmed that Poldip2 acts upstream of Nox4 in lung epithelial cells, but whether Poldip2 functionally regulates NADPH enzymatic activity needs further research.

4.3. Effect of Poldip2 on LPS-Induced Oxidative Stress and Inflammation. To further investigate the role of Poldip2 in 


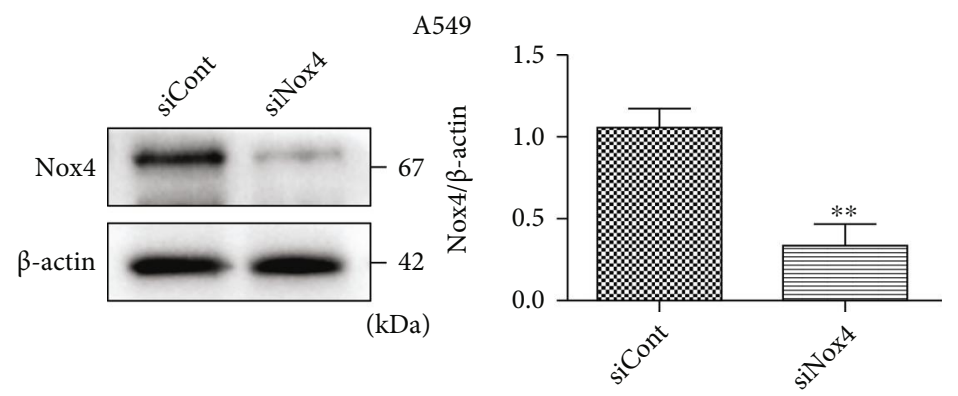

(a)

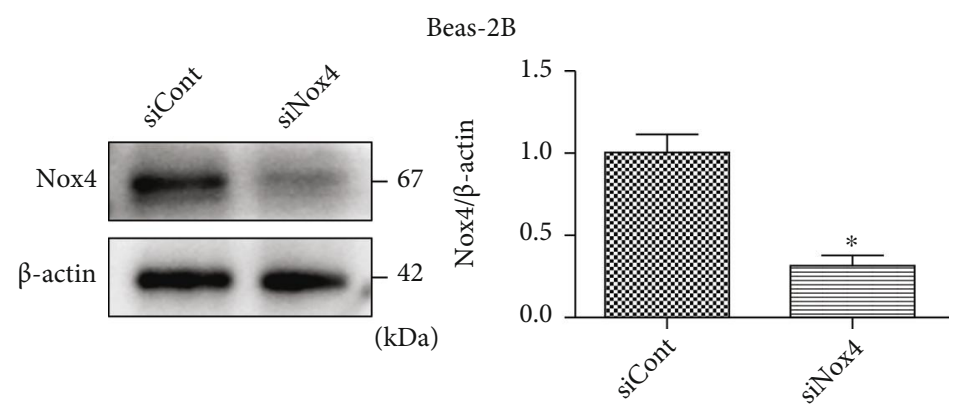

(b)
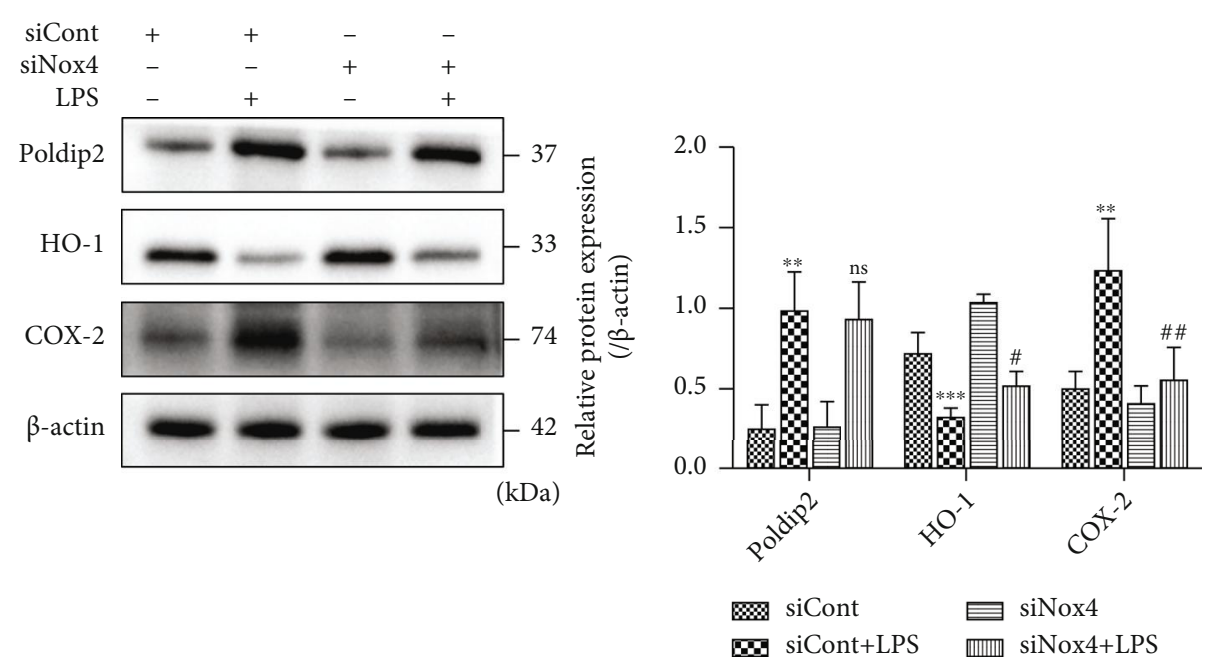

(c)

FIgURE 3: Continued. 


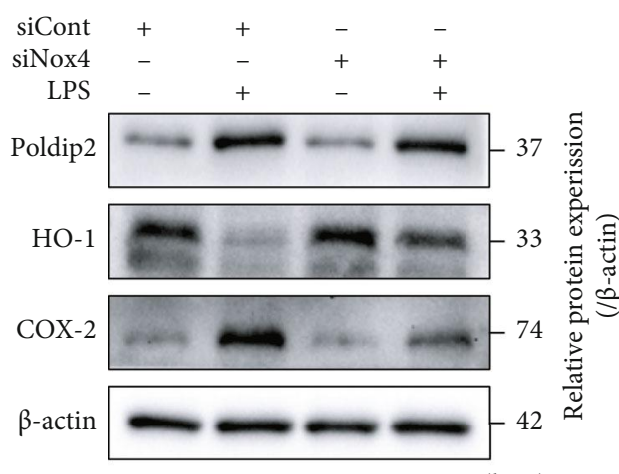

$(\mathrm{kDa})$

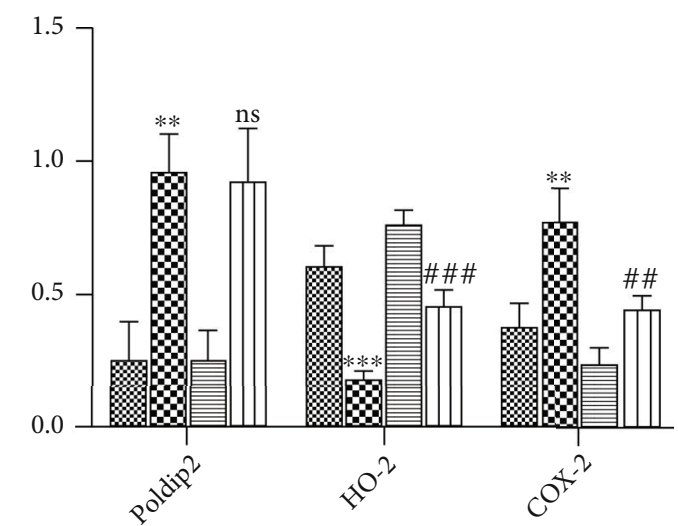

Sicount

亳 SiNox4

$\$$ Sicount+LPS $\square$ SiNox4+LPS

(d)
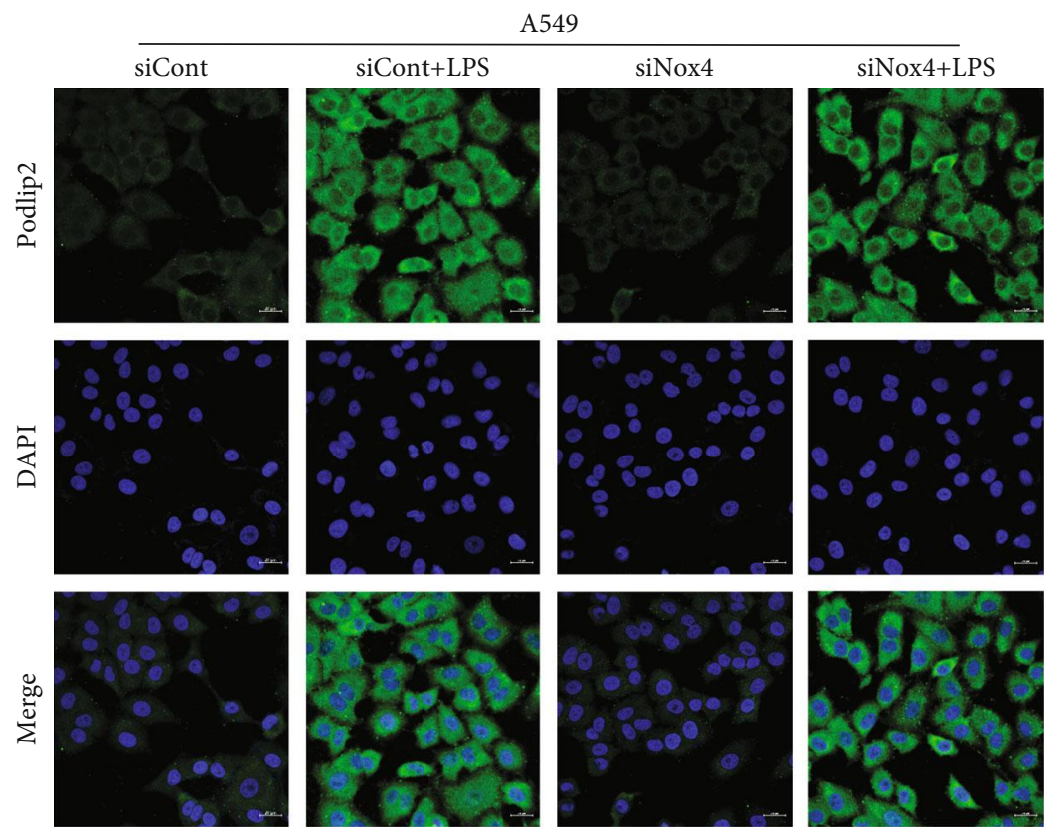

(e)

FIgURE 3: Continued. 


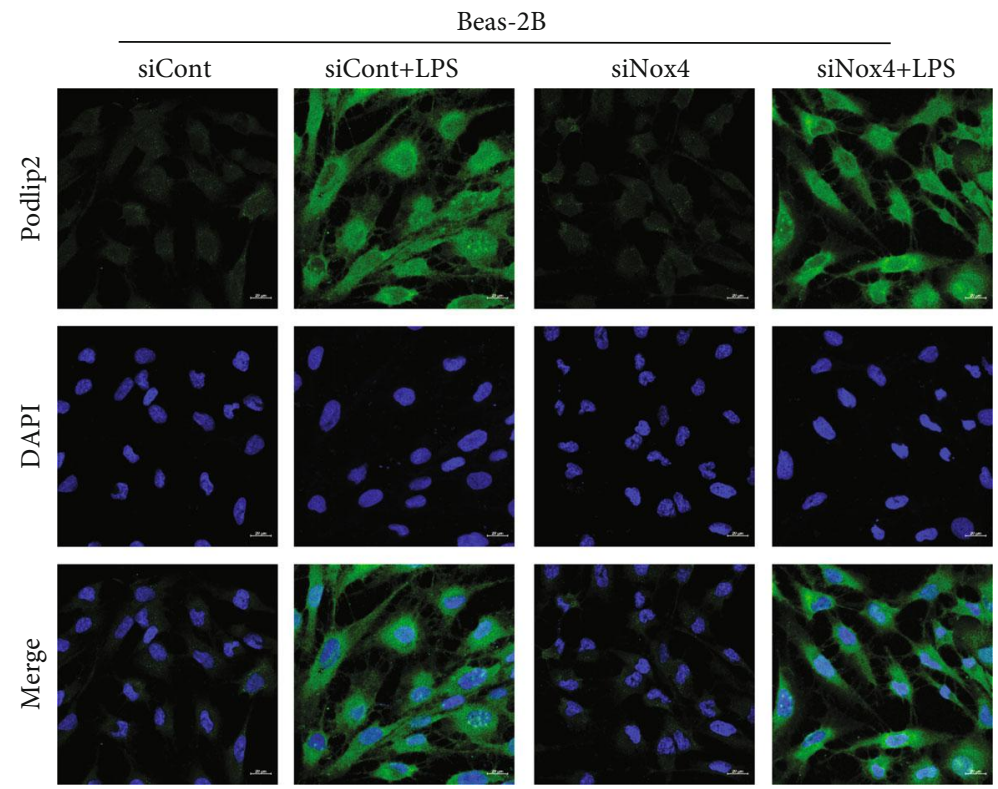

(f)

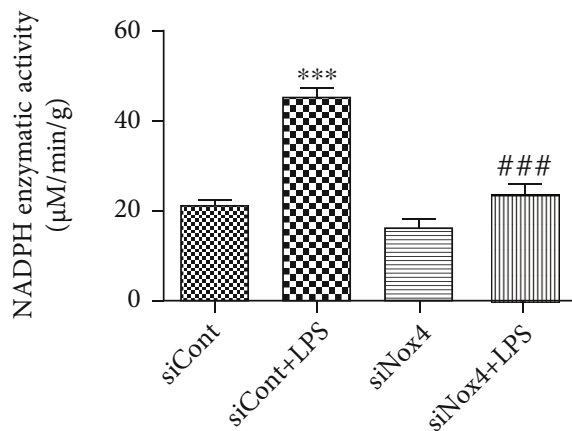

(h)

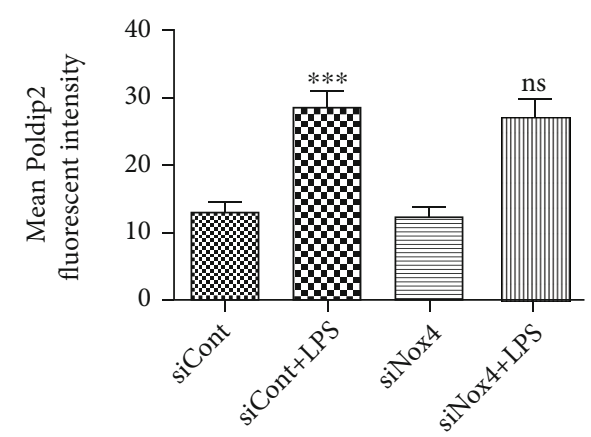

(i)

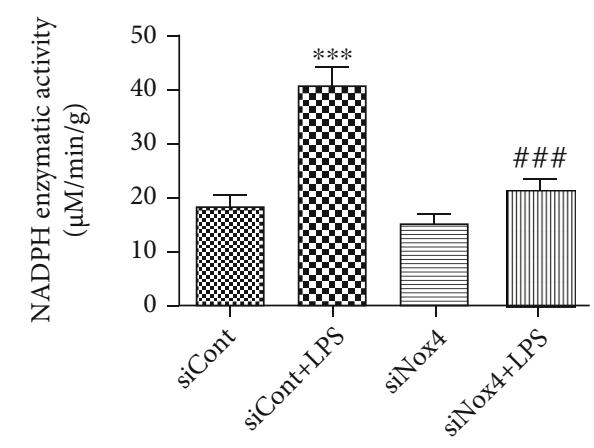

(j)

Figure 3: Continued. 


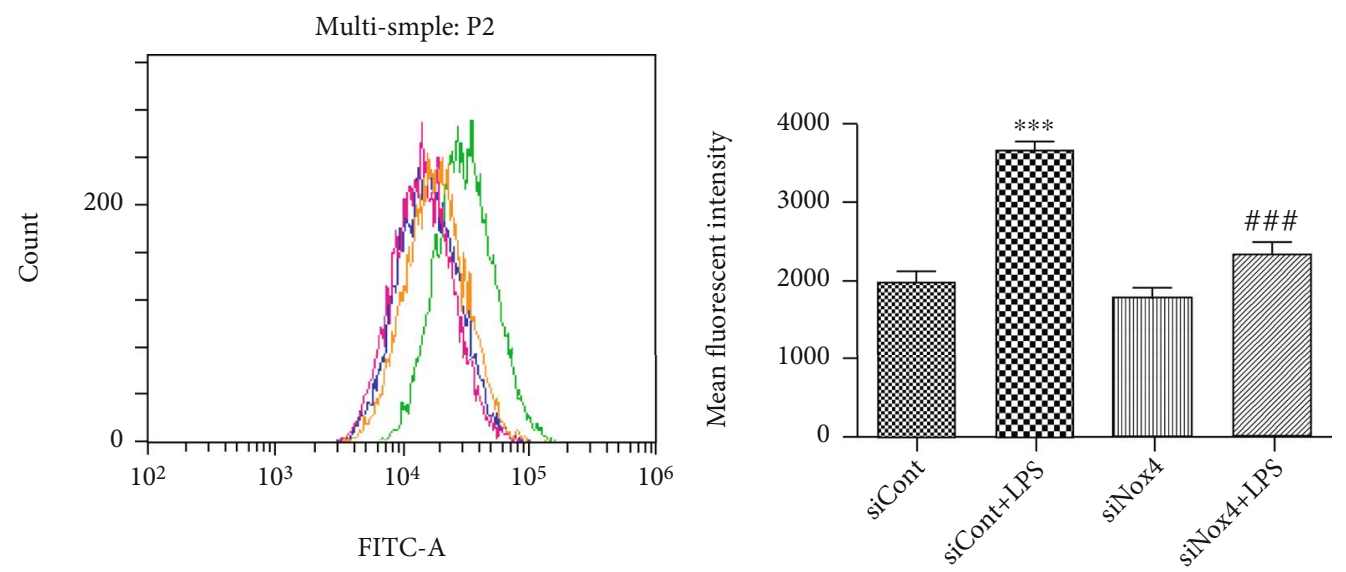

(k)
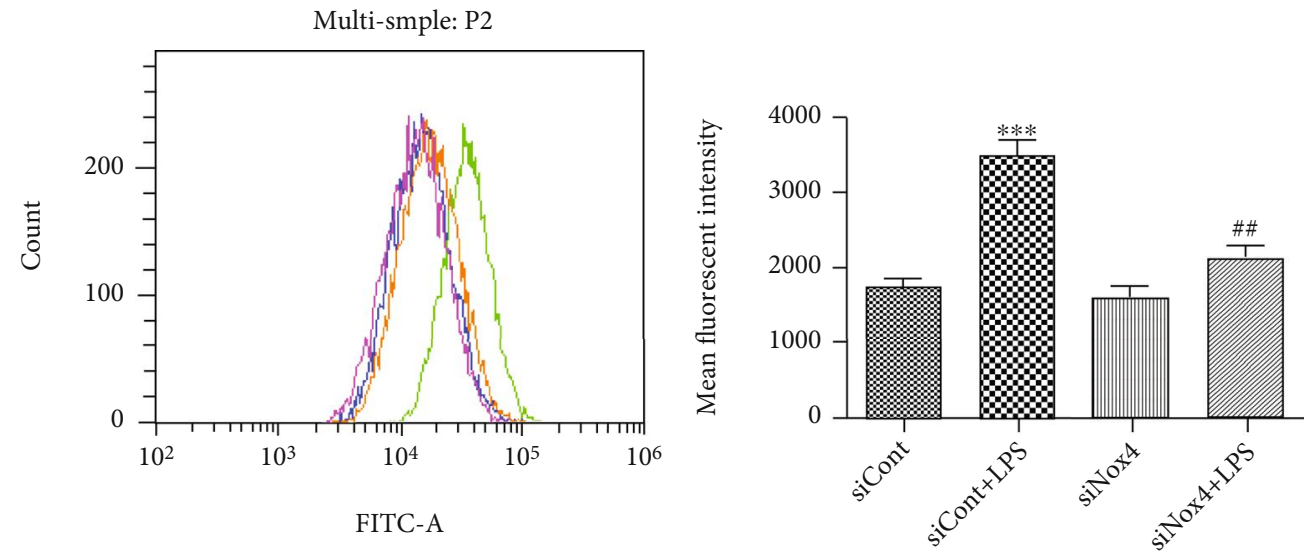

FITC-A

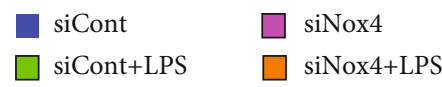

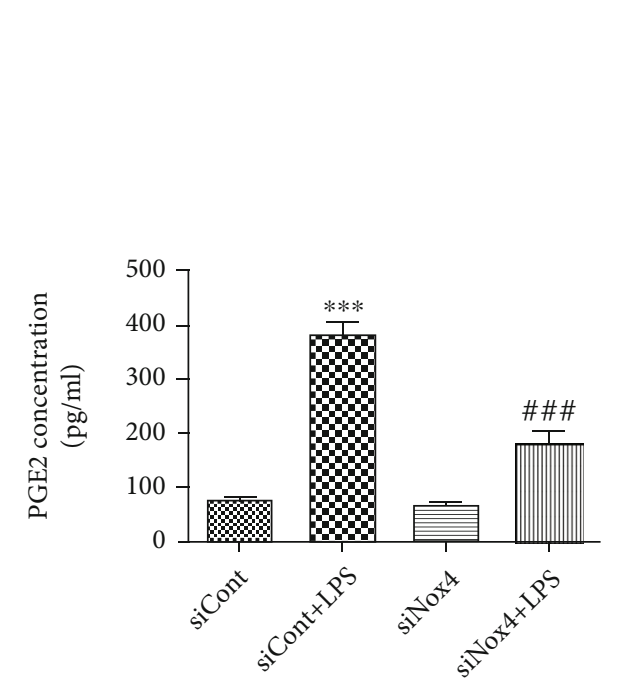

(m)

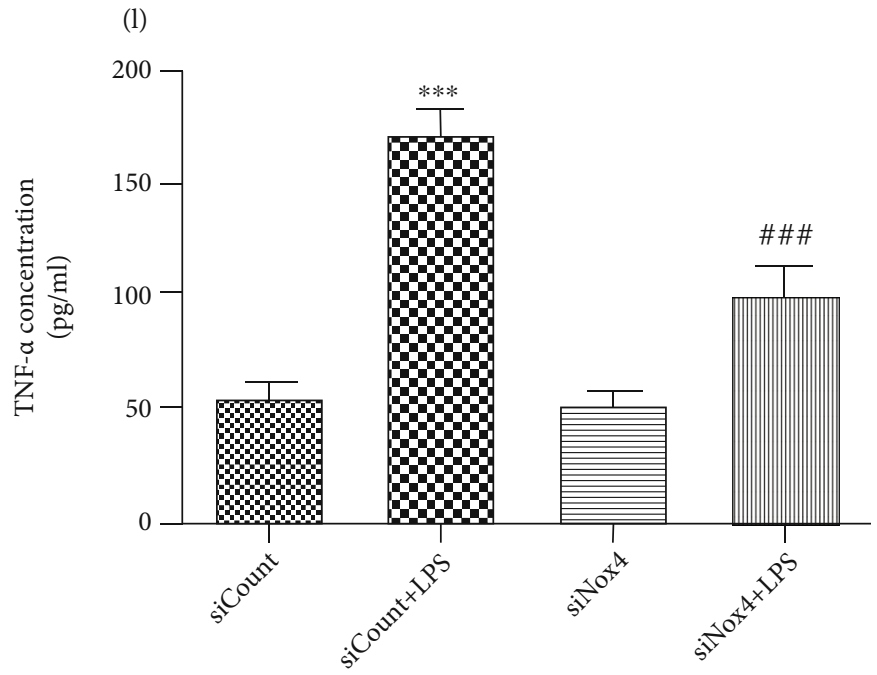

(n)

FIgUre 3: Continued. 


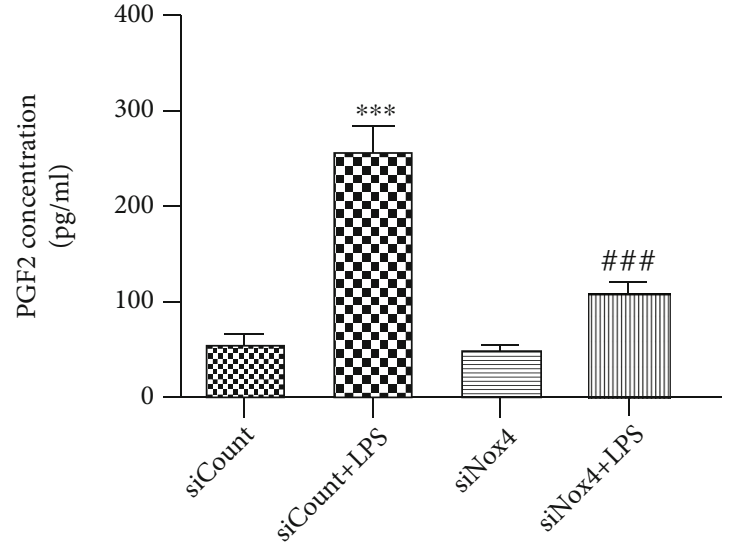

(o)

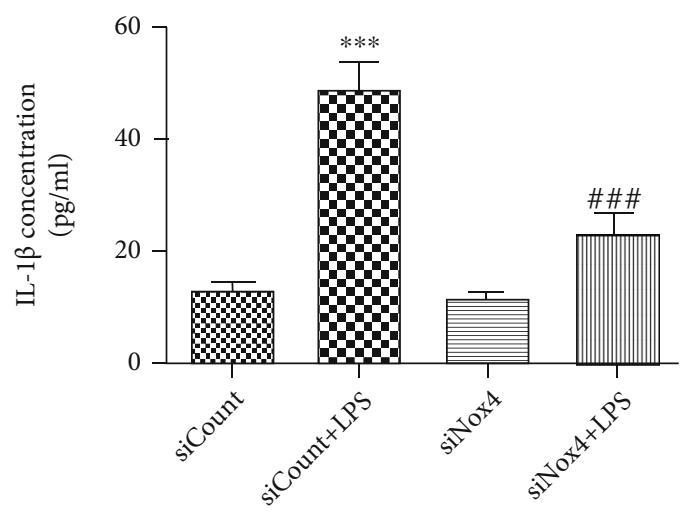

(q)

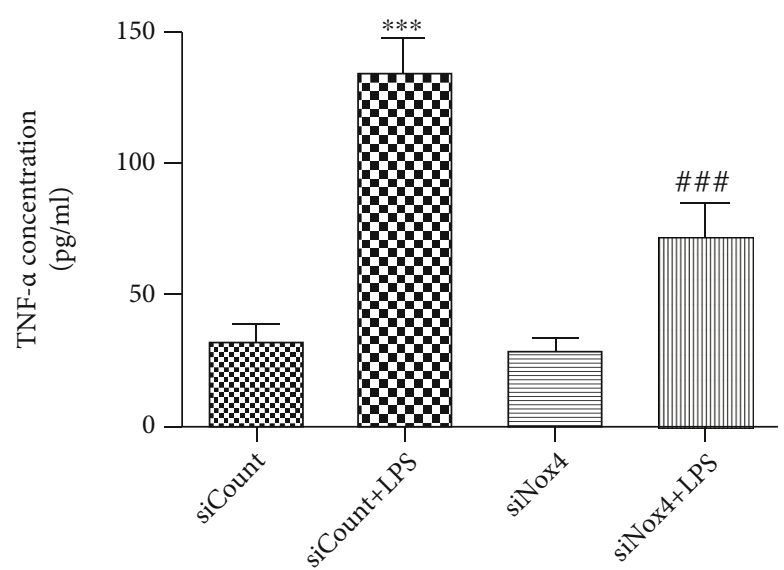

$(\mathrm{p})$

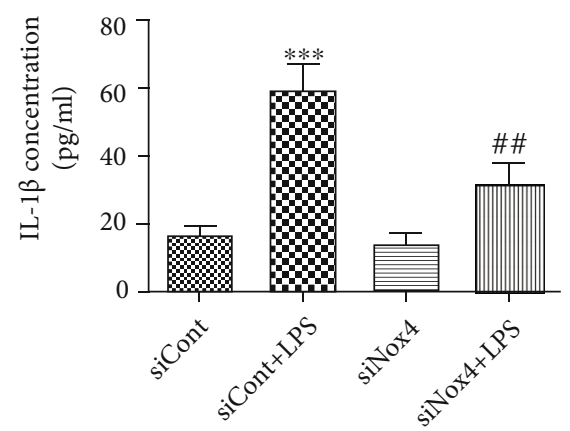

$(\mathrm{r})$

FIgure 3: Nox4 is required for Poldip2 to exert action in response to LPS. (a, b) Confluent A549 and Beas-2B cells were transfected with siRNA for $72 \mathrm{~h}$, and the efficiency of Nox4 downregulation was verified by Western blotting and quantitatively analyzed. Following transfection, they were treated with LPS $(10 \mu \mathrm{g} / \mathrm{mL}$ for A549 cells and $1 \mu \mathrm{g} / \mathrm{mL}$ for Beas-2B cells) for $12 \mathrm{~h}$. (c, d) The protein levels of Poldip2, HO-1, and COX-2 were detected by Western blotting and quantitatively analyzed. (e-g, i) The expression of Poldip2 was detected by immunofluorescence analysis and laser confocal microscope. The cells were stained with Poldip2 (green) and counter stained with DAPI (blue) (magnification of 400x). (h, j) The NADPH enzymatic activity in cells was detected by spectrophotometer. (k, l) The production of intracellular ROS was detected by flow cytometry. (m-r) The expression levels of PGE2, TNF- $\alpha$, and IL-1 $\beta$ in the supernatant were detected by ELISA. Bars are mean \pm SD of 3 independent experiments. ns: not significant, ${ }^{* * *} P<0.001$ vs. siCont, ${ }^{* *} P<0.01$ vs. siCont, ${ }^{*} P<0.05$ vs. siCont, \#\#\# $P<0.001$ vs. siCont + LPS, ${ }^{\# \# ~} P<0.01$ vs. siCont + LPS, and ${ }^{\#} P<0.05$ vs. siCont + LPS.

LPS-induced oxidative stress and inflammation, we transfected A549 and Beas-2B cells with lentiviruses harboring short hairpin RNA (shRNA) against Poldip2 (shPoldip2) to downregulate Poldip2 expression and compared with the control lentivirus vector without construct (shCont) (Figures 5(a) and 5(b)). Transfected cells (shCont and shPoldip2) were treated with PBS or LPS for $12 \mathrm{~h}$. We found that downregulation of Poldip2 via shPoldip2 markedly inhibited LPS-induced increases in the expression of Nox4 (Figures 5(c) and 5(d)), enzymatic activity of NADPH oxidases (Figures 5(h) and 5(j)), and ROS generation (Figures 5(k) and 5(l)). Immunofluorescence analyses (Figures 5(e)-5(g) and 5(i)) were consistent with the results of Western blotting in Figures 5(c) and 5(d). Meanwhile, downregulation of Poldip2 resulted in markedly enhanced HO-1 expression but attenuated COX-2 expression (Figures 5(c) and 5(d)) under LPS stimulation. Accordingly, the production of PGE2, TNF- $\alpha$, and IL- $1 \beta$ was also decreased by Poldip 2 downregulation (Figures $5(\mathrm{~m})-5(\mathrm{r})$ ).
Conversely, we transfected lentivirus-upregulating Poldip 2 particles to upregulate the Poldip2 expression. The results showed that Poldip2 upregulation (LvPoldip2) caused a significant increase of the Poldip2 protein level comparing with the control (LvCont) (Figures 6(a) and 6(b)). Then, transfected cells (LvCont and LvPoldip2) were treated as mentioned above. We also found that upregulation of Poldip2 exaggerated LPS-induced increases in the expression of Nox4 (Figures 6(c) and 6(d)), enzymatic activity of NADPH oxidases (Figures $6(\mathrm{~h})$ and $6(\mathrm{j})$ ), and ROS generation (Figures 6(k) and 6(l)). Immunofluorescence analyses (Figures 6(e)-6(g) and 6(i)) were consistent with the results of Western blotting in Figures 6(c) and 6(d). Meanwhile, upregulation of Poldip2 resulted in markedly attenuated HO-1 expression but enhanced COX-2 expression (Figures 6(c) and 6(d)) under LPS stimulation. Similarly, Poldip2 upregulation significantly exaggerated the LPS-induced increase in PGE2, TNF- $\alpha$, and IL- $1 \beta$ production (Figures $6(\mathrm{~m})-6(\mathrm{r})$ ). Collectively, these data indicated 


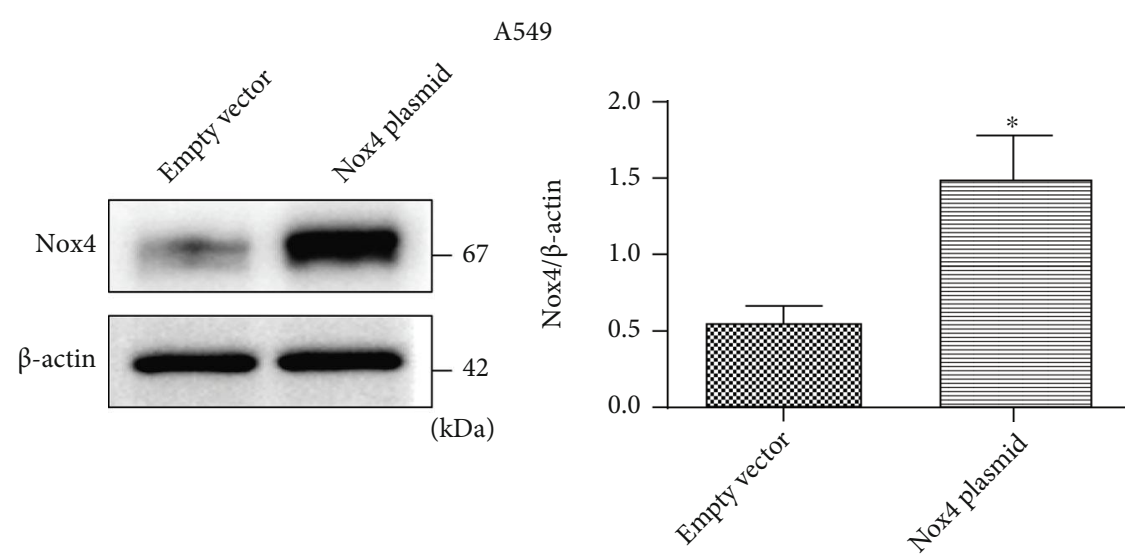

(a)

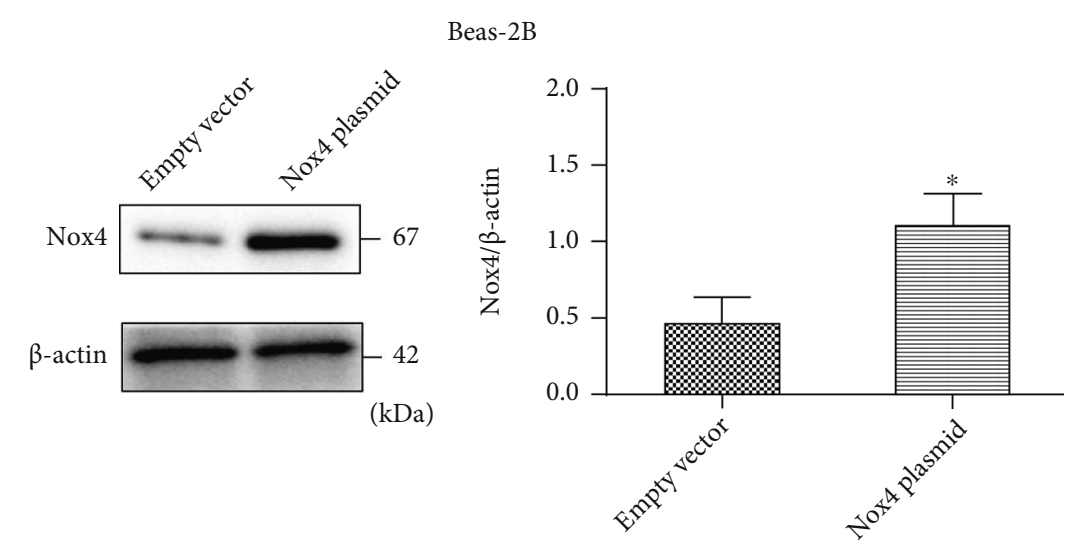

(b)
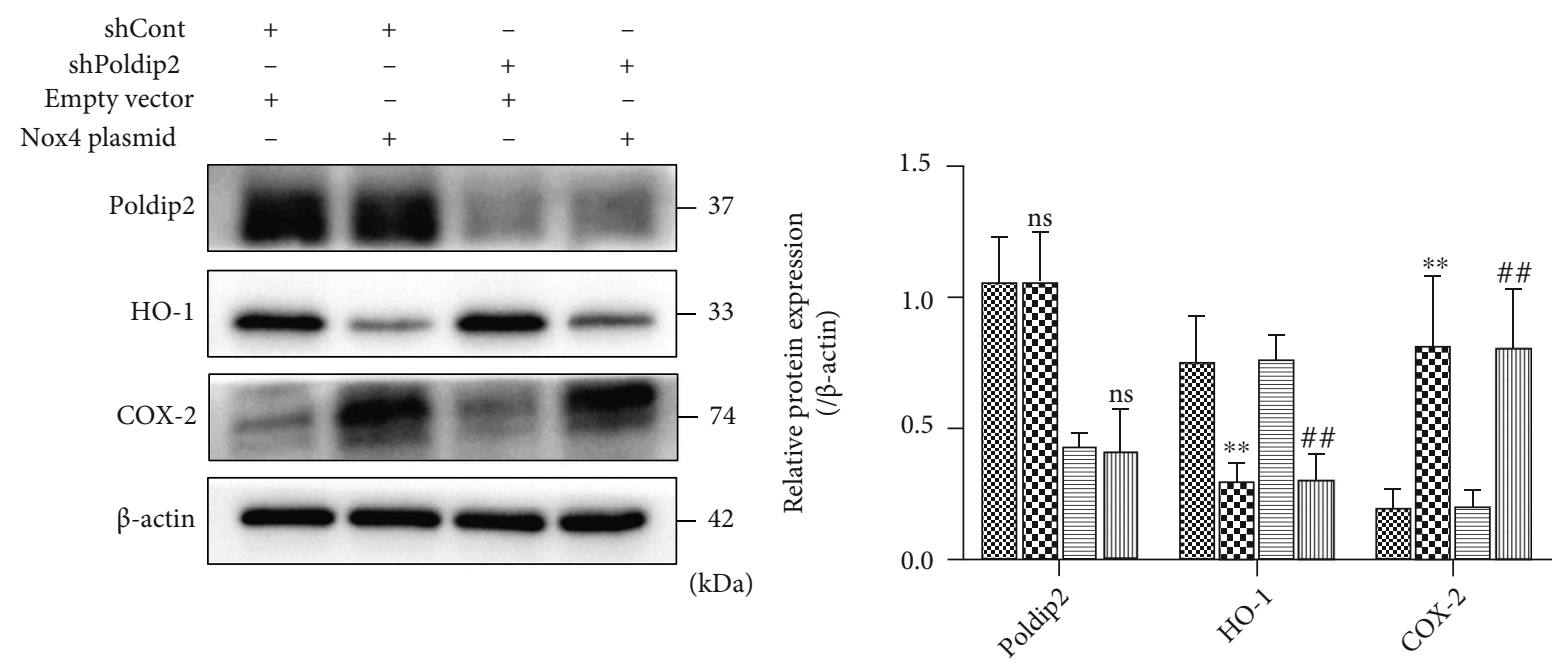

Wh sheont+empty vector

E8 shCont+Nox4 plasmid

shPoldip2+empty vector

而 shPoldip2+Nox4 plasmid

(c)

Figure 4: Continued. 

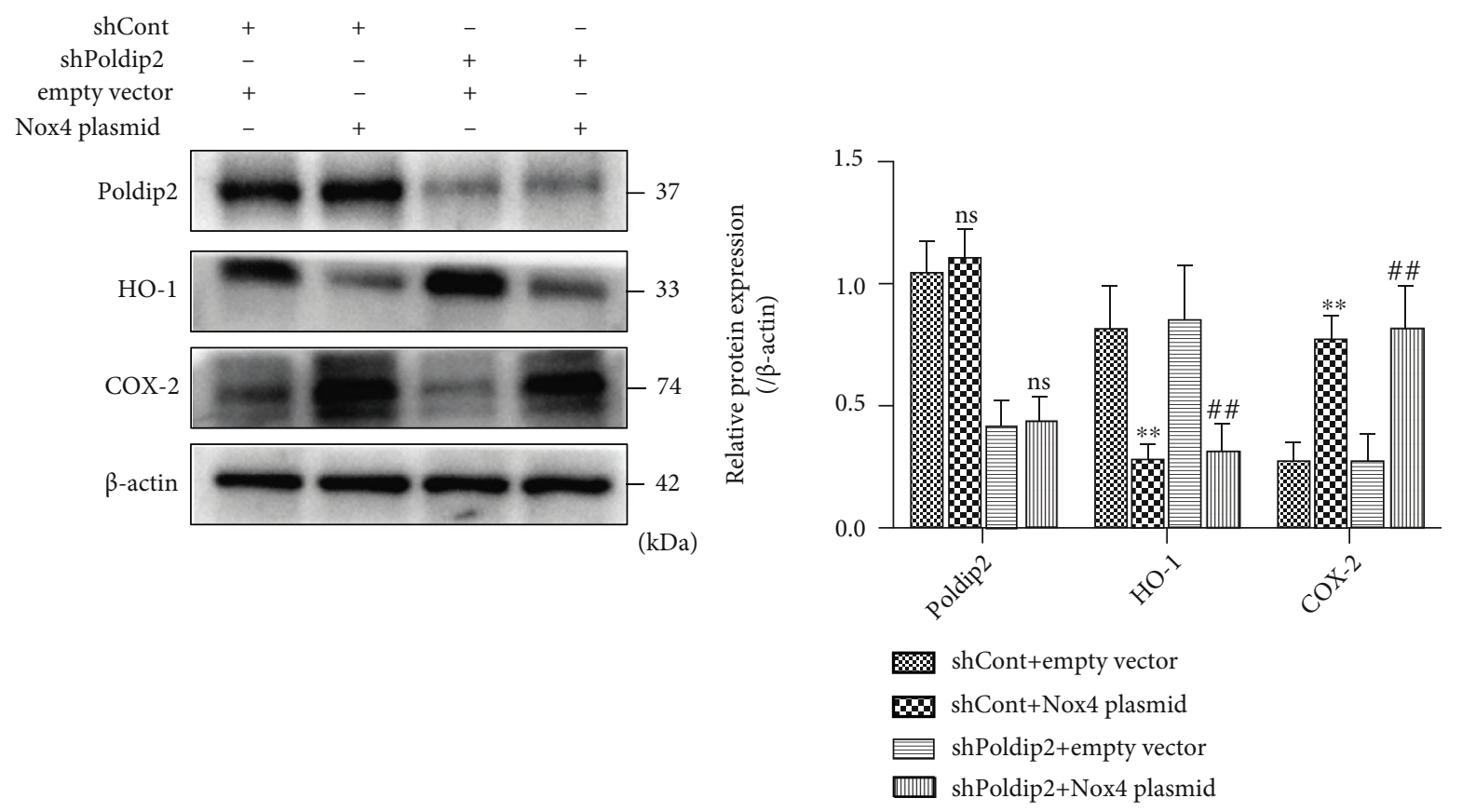

(d)
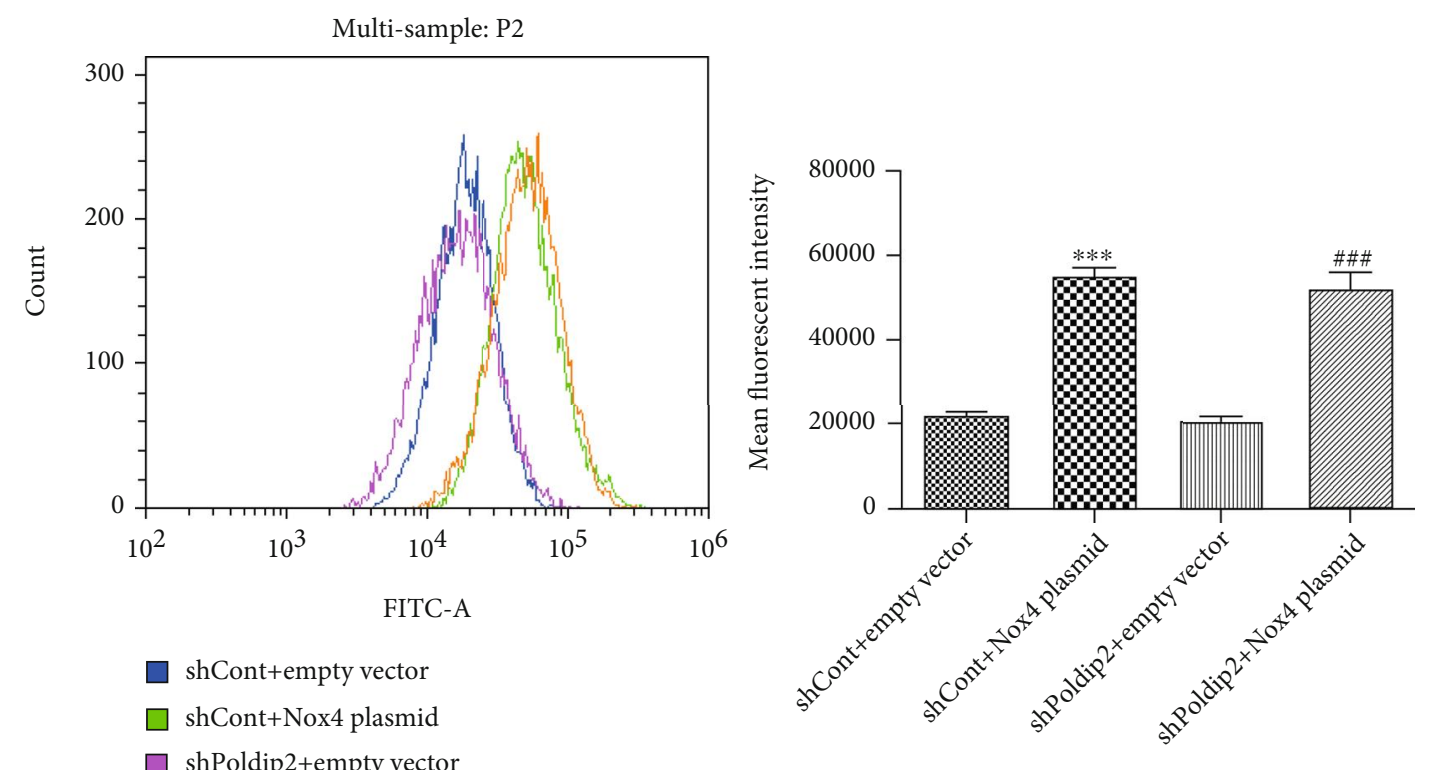

shCont+empty vector

shCont+Nox4 plasmid

shPoldip2+empty vector

$\square$ shPoldip2+Nox4 plasmid

(e)

FIgURE 4: Continued. 

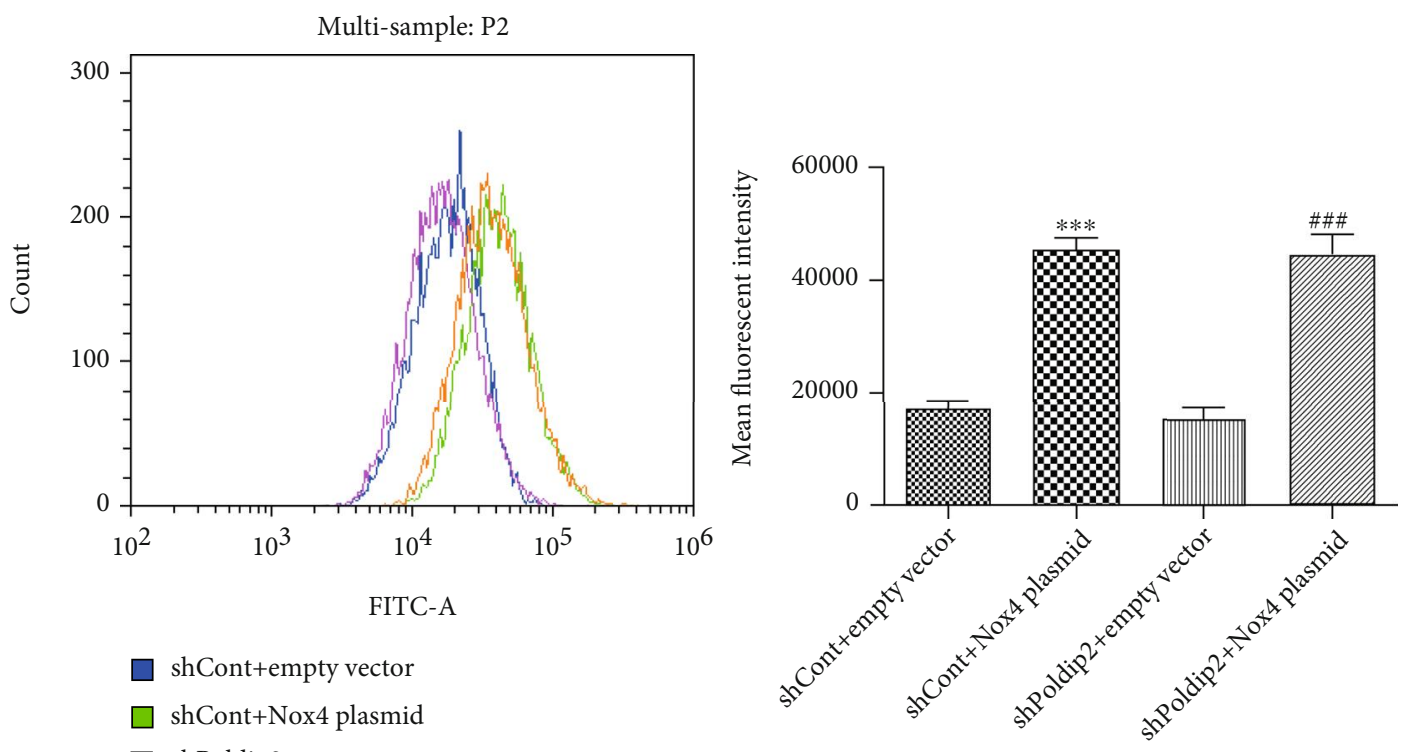

$\square$ shCont+empty vector

$\square$ shCont+Nox4 plasmid

shPoldip2+empty vector

shPoldip2+Nox4 plasmid

(f)

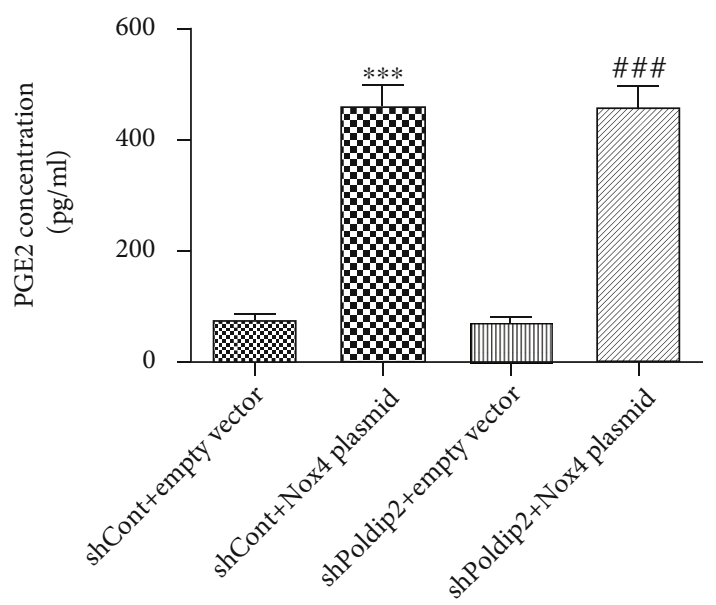

(g)

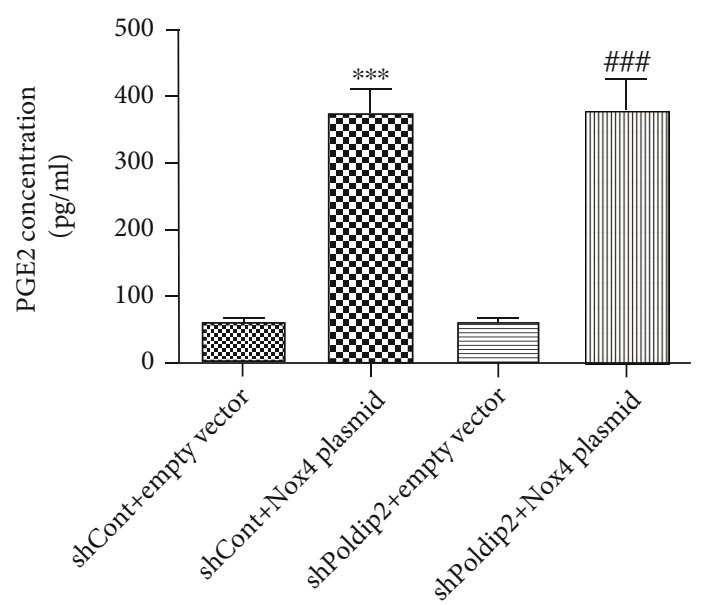

(i)

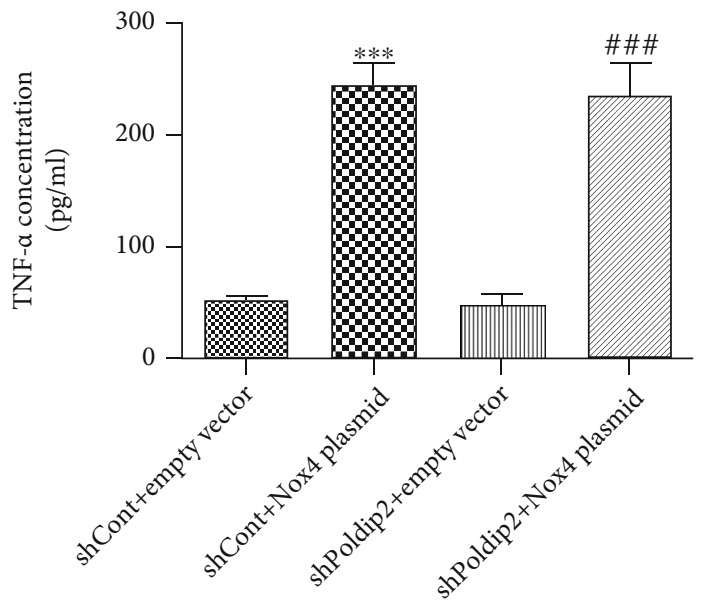

(h)

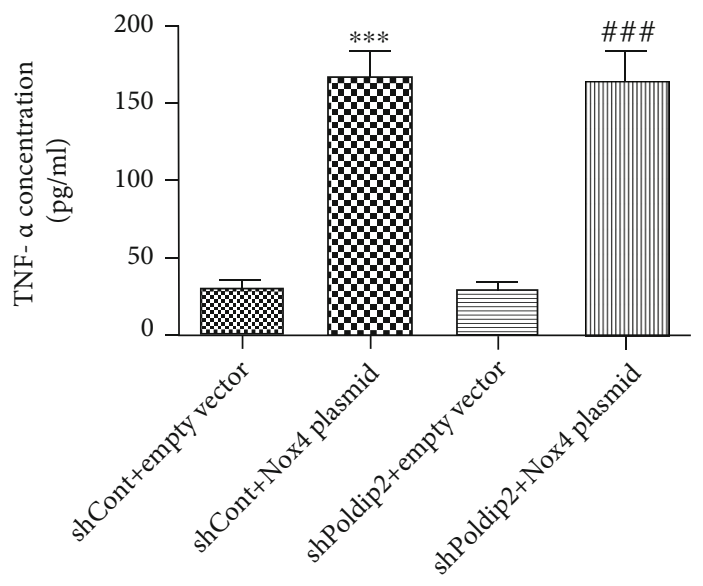

(j)

FIgUre 4: Continued. 


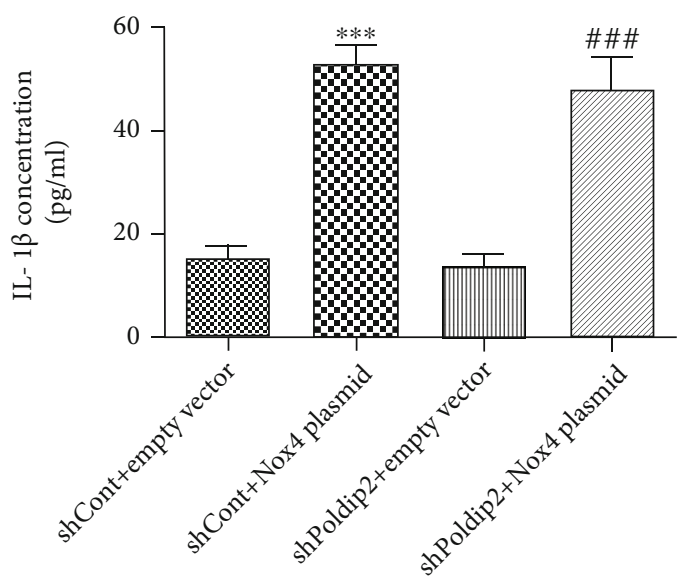

(k)

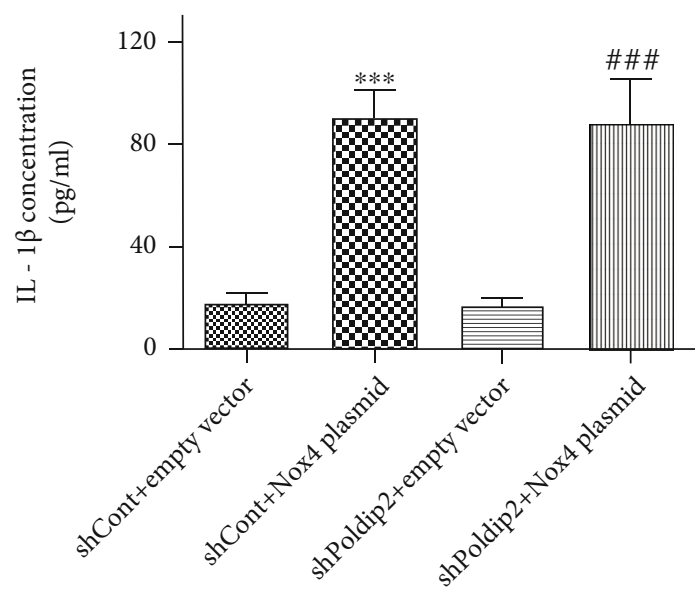

(1)

Figure 4: Upregulation of Nox4 increased oxidative stress and inflammation. (a, b) Confluent A549 and Beas-2B cells were transfected with Nox4 plasmid or the empty vector for $72 \mathrm{~h}$, and the efficiency of Nox4 upregulation was verified by Western blotting and quantitatively analyzed. Confluent shCont and shPoldip 2 cells were cotransfected with Nox4 plasmid or the empty vector for $72 \mathrm{~h}$. (c, d) The protein levels of Poldip2, HO-1, and COX-2 were detected by Western blotting and quantitatively analyzed. (e, f) The production of intracellular ROS was detected by flow cytometry. (g-l) The expression levels of PGE2, TNF- $\alpha$, and IL- $1 \beta$ in the supernatant were detected by ELISA. Bars are mean \pm SD of 3 independent experiments. ${ }^{* * *} P<0.001$ vs. shCont + empty vector, ${ }^{* *} P<0.01$ vs. shCont + empty vector, ${ }^{*} P<0.05$ vs. empty vector, ${ }^{\# \# \# ~} P<0.001$ vs. shPoldip $2+$ empty vector, and ${ }^{\# \#} P<0.01$ vs. shPoldip $2+$ empty vector.

that Poldip2 might be responsible for LPS-induced oxidative stress and inflammation via mediated Nox4 activation.

4.4. Role of Poldip2/Nox4-Mediating Oxidative Stress and Inflammation Was Dependent on PI $3 K-A K T$ Signaling. As previously mentioned, Poldip2 interacted with Nox4 in response to LPS stimulation and acted as a vital regulator of Nox4. PI3K-AKT signaling has been proven to increase the expression of NADPH oxidases via upregulating its regulatory subunit in mammalian cells [21]. Here, we further explored a role for the PI3K-AKT signaling in the activation of Poldip2/Nox4 in response to LPS and cells were pretreated with the PI3K inhibitor LY294002 $(10 \mu \mathrm{mol} / \mathrm{L}$, final concentration, dissolved in DMSO) for $1 \mathrm{~h}$ followed by postincubation with LPS for $12 \mathrm{~h}$. As shown in Figures 7(a) and 7(b), we determined the activation of PI3K-AKT signaling by analyzing the phosphorylation of its key effector, pAKT, via Western blotting. LPS stimulation significantly increased the p-AKT expression, which was partially suppressed by pretreatment with LY294002. Importantly, the results showed that inhibition of PI3K resulted in a reduction in LPS-induced increases in Poldip2, Nox4, and COX2 , as well as decreases in HO-1 expression. Immunofluorescence analyses (Figures 7(c)-7(h)) were consistent with the results of Western blotting in Figures 7(a) and 7(b). Collectively, these data above suggest that PI3K-AKT signaling is required for the LPS-mediated Poldip2/Nox4 activation.

\section{Discussion}

In this study, our data demonstrated that LPS induced oxidative stress and inflammation in lung epithelial cells by increasing the expression of Nox 4 and COX-2 and NADPH enzymatic activity and substantially increasing the production of ROS, PGE2, TNF- $\alpha$, and IL- $1 \beta$ and decreasing the HO-1 expression. Remarkably, Poldip2, a novel regulator of Nox4, interacted with Nox4 and acted as an upstream regulator of Nox4 in LPS-stimulated lung epithelial cells. By downregulation or upregulation of Poldip2, we confirmed that Nox4 requires Poldip2 for ROS generation and subsequent inflammation. Taken together, our findings reveal that Poldip2 mediates oxidative stress and inflammation via interaction with Nox4 and such effect of Poldip2/Nox4 is regulated by the PI3K-AKT signaling in LPS-stimulated lung epithelial cells. Our results suggest that Poldip2 may be a potential therapeutic candidate for the treatment of ALI.

It is well known that LPS stimulation can induce excessive ROS generation that exaggerated a range of respiratory inflammatory diseases, such as chronic obstructive pulmonary disease (COPD), asthma, and ALI [22]. NADPH oxidase was an important source for the generation of ROS [23]. Distinct from other members of the NADPH oxidase, Nox 4 was constitutively active and played a detrimental role in the development of inflammatory diseases [24, 25]. Both A549 and Beas-2B cells are commonly used to investigate the cellular mechanism of lung inflammation under LPS stimulation, including oxidative stress and autophagy [26, 27]. Herein, our results showed clearly that LPS significantly increased NOX4 expression in lung epithelial cells in dose-/ time-dependent manners, which were paralleled to the expression of Poldip2. Over the years, Poldip2 is emerging as an important mediator in inflammatory diseases, including sepsis-associated encephalopathy [28] and ARDS [13]. Previous findings have demonstrated that heterozygous deletion of Poldip 2 or Nox4 knockdown markedly reduces superoxide production and improves survival in the ALI/ 

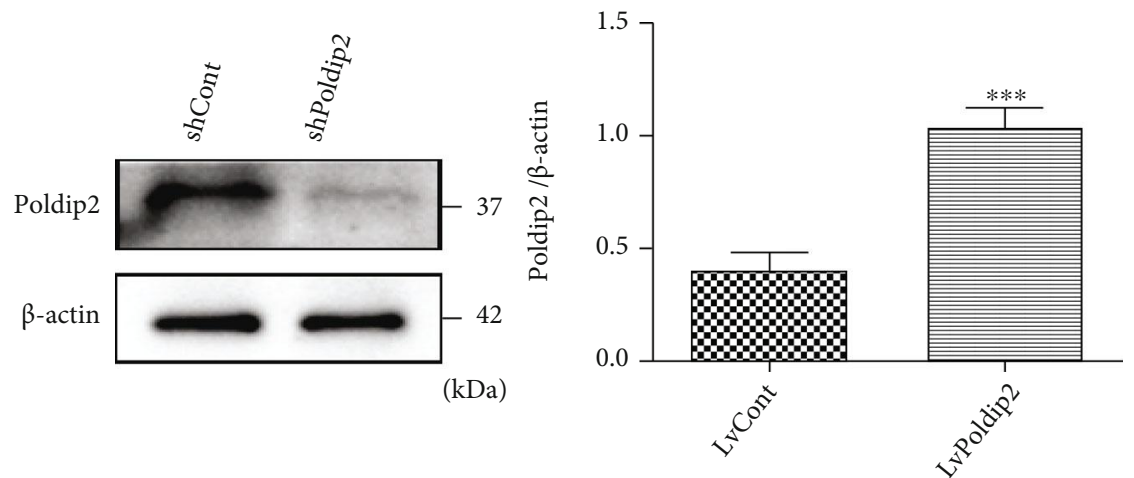

(a)

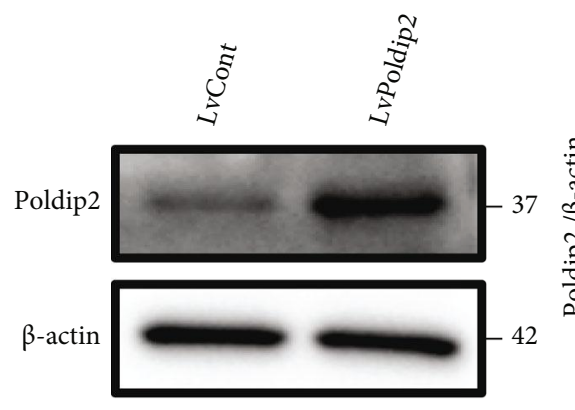

$(\mathrm{kDa})$

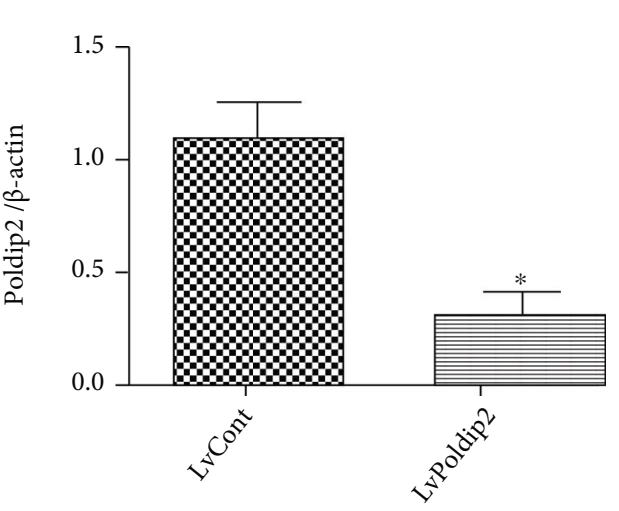

(b)
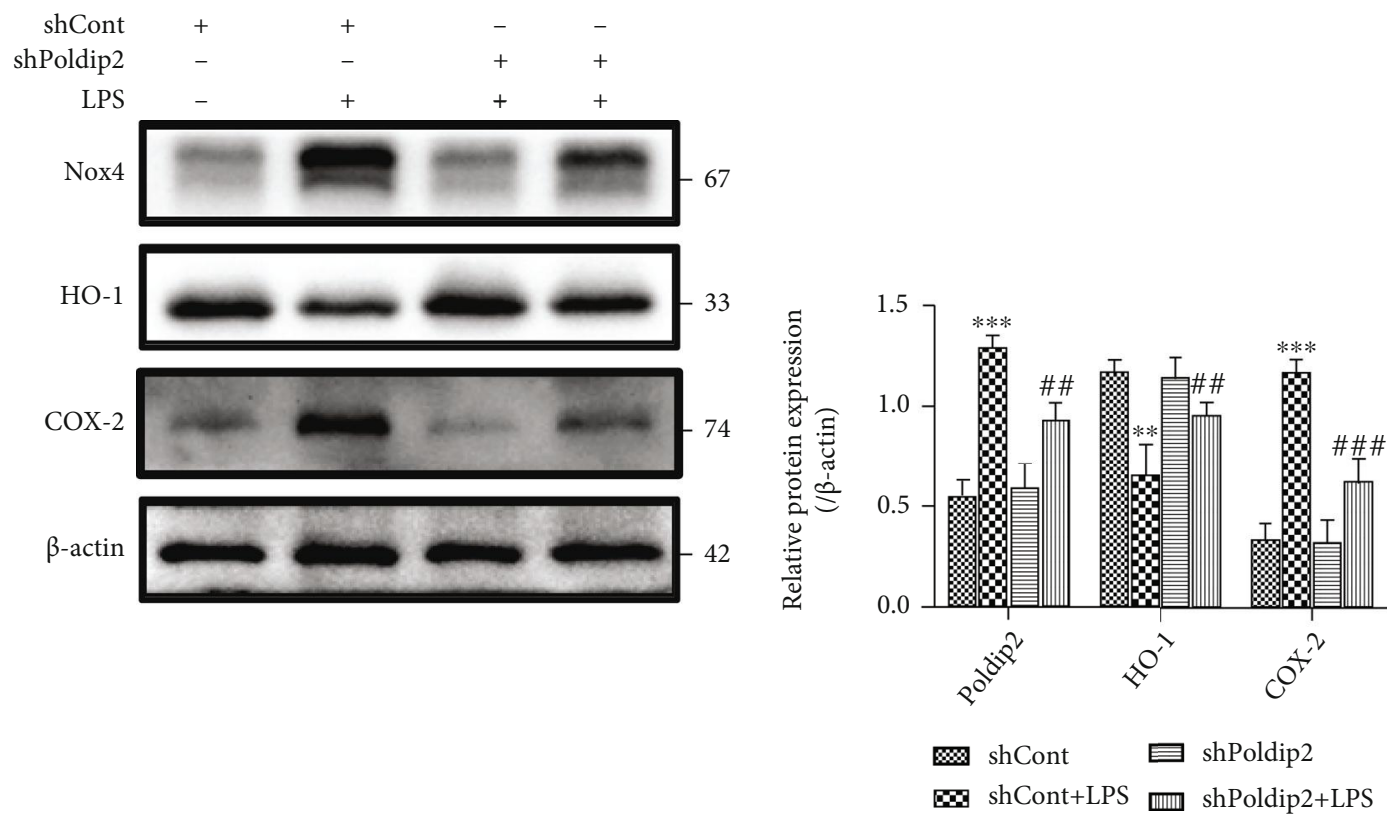

(c)

Figure 5: Continued. 

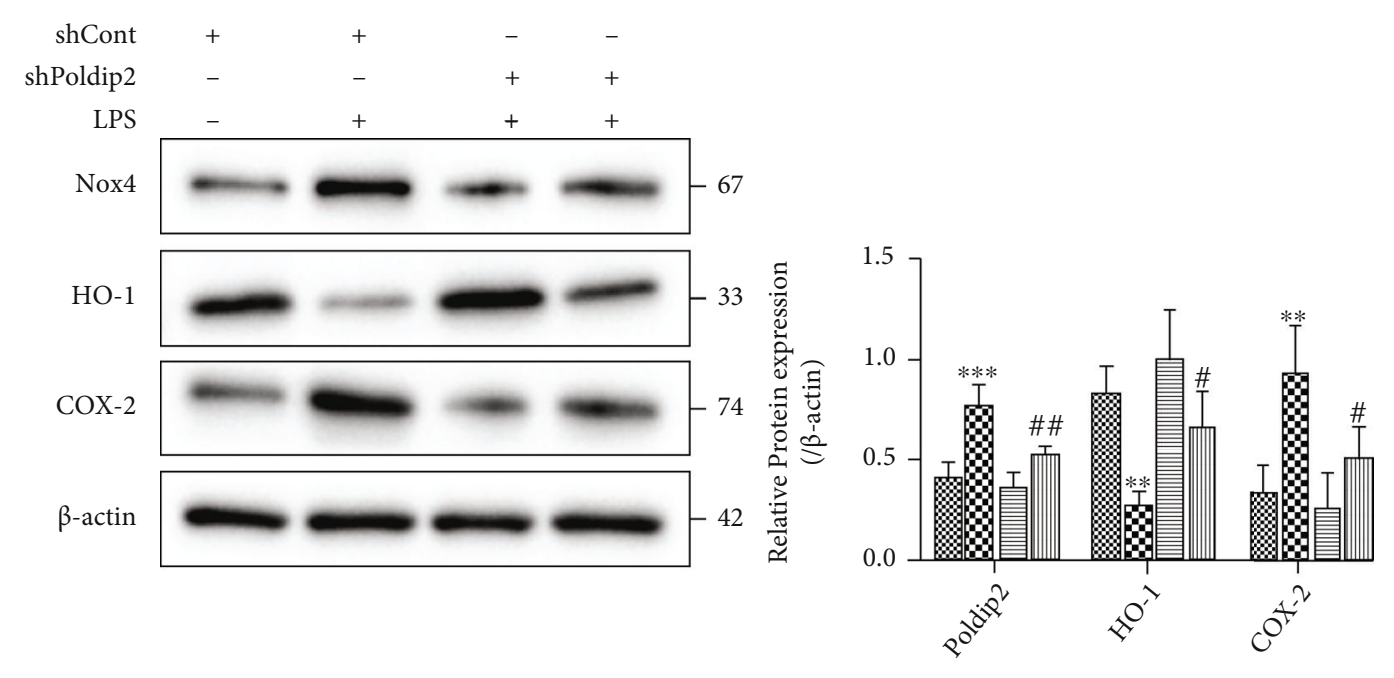

\& shCont $\square$ shPoldip2

shCont+LPS

(d)

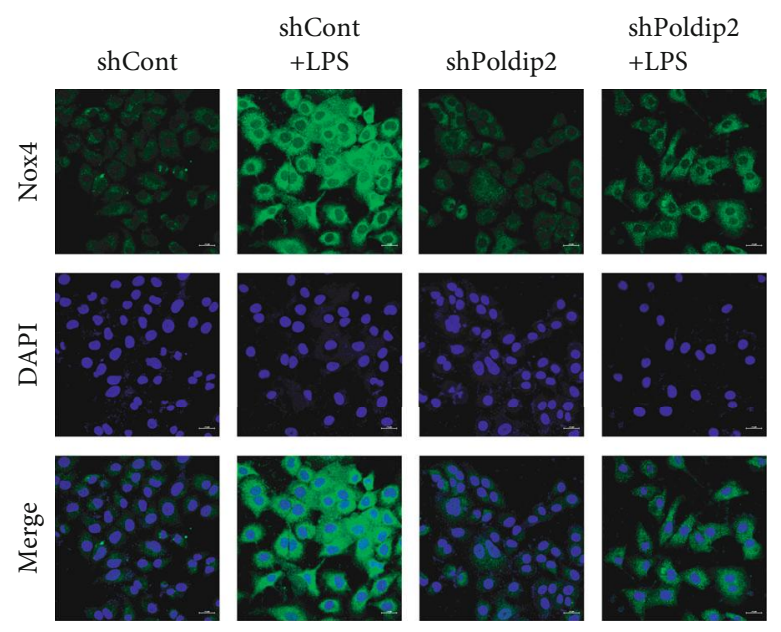

(e)

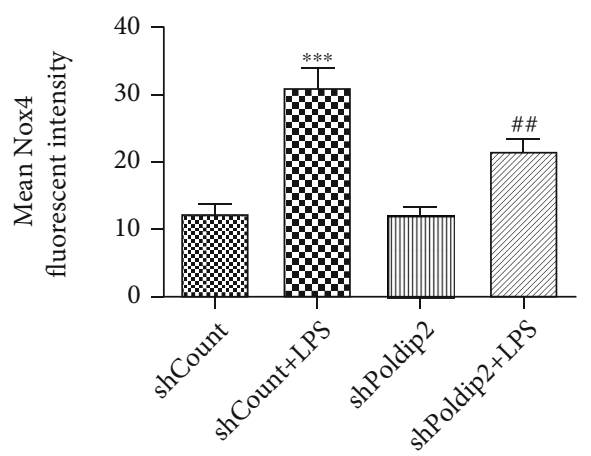

(g)

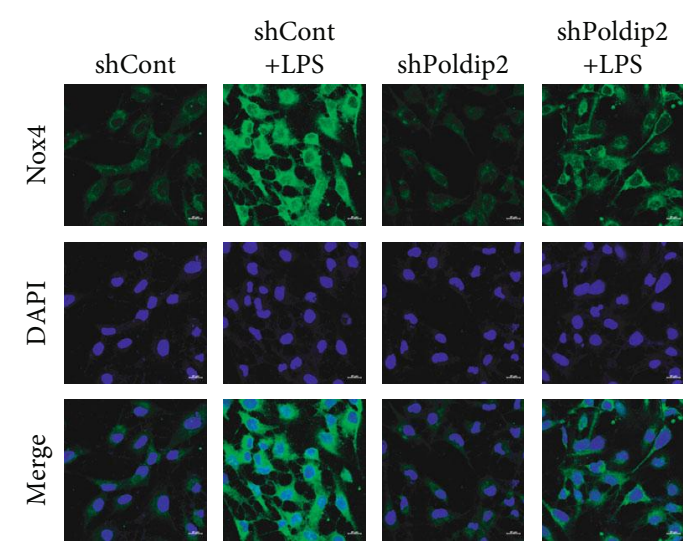

(f)

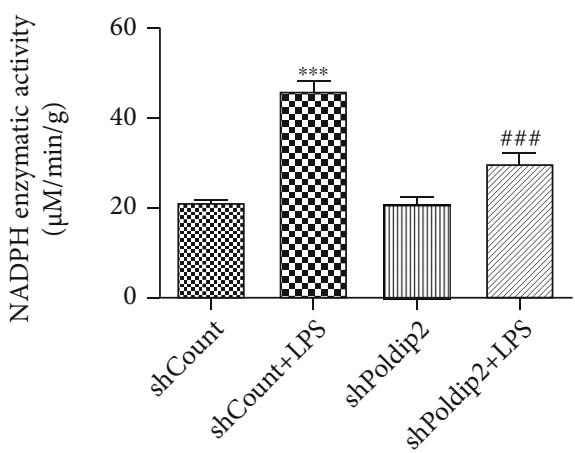

(h)

Figure 5: Continued. 


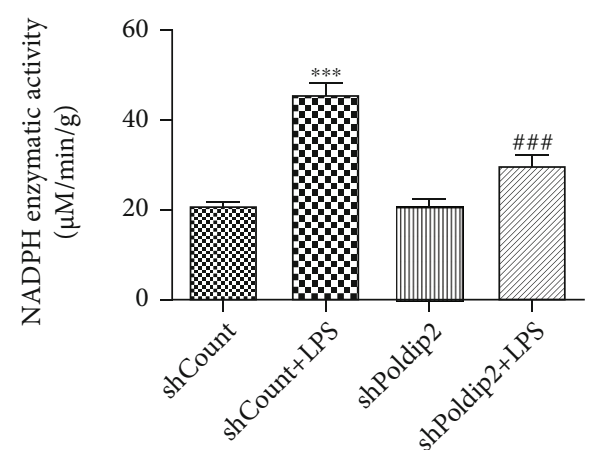

(i)

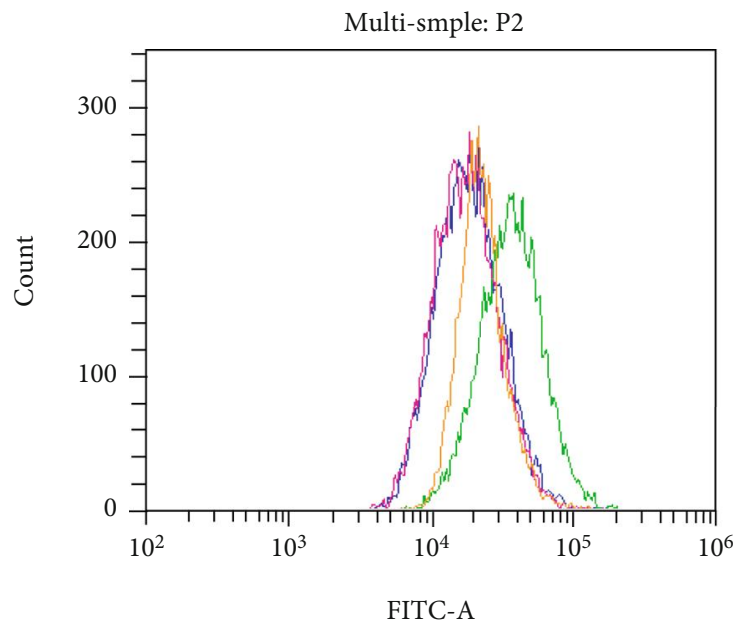

(k)

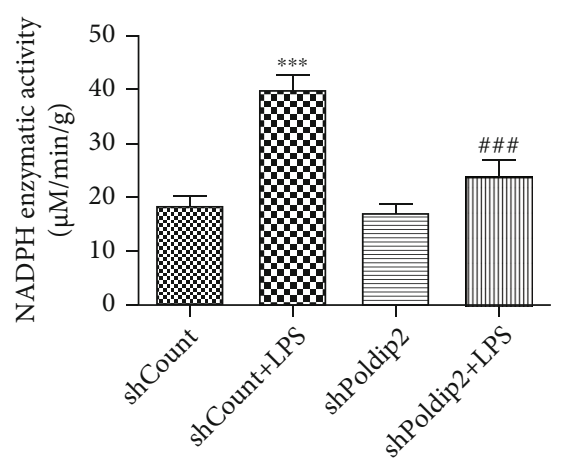

(j)
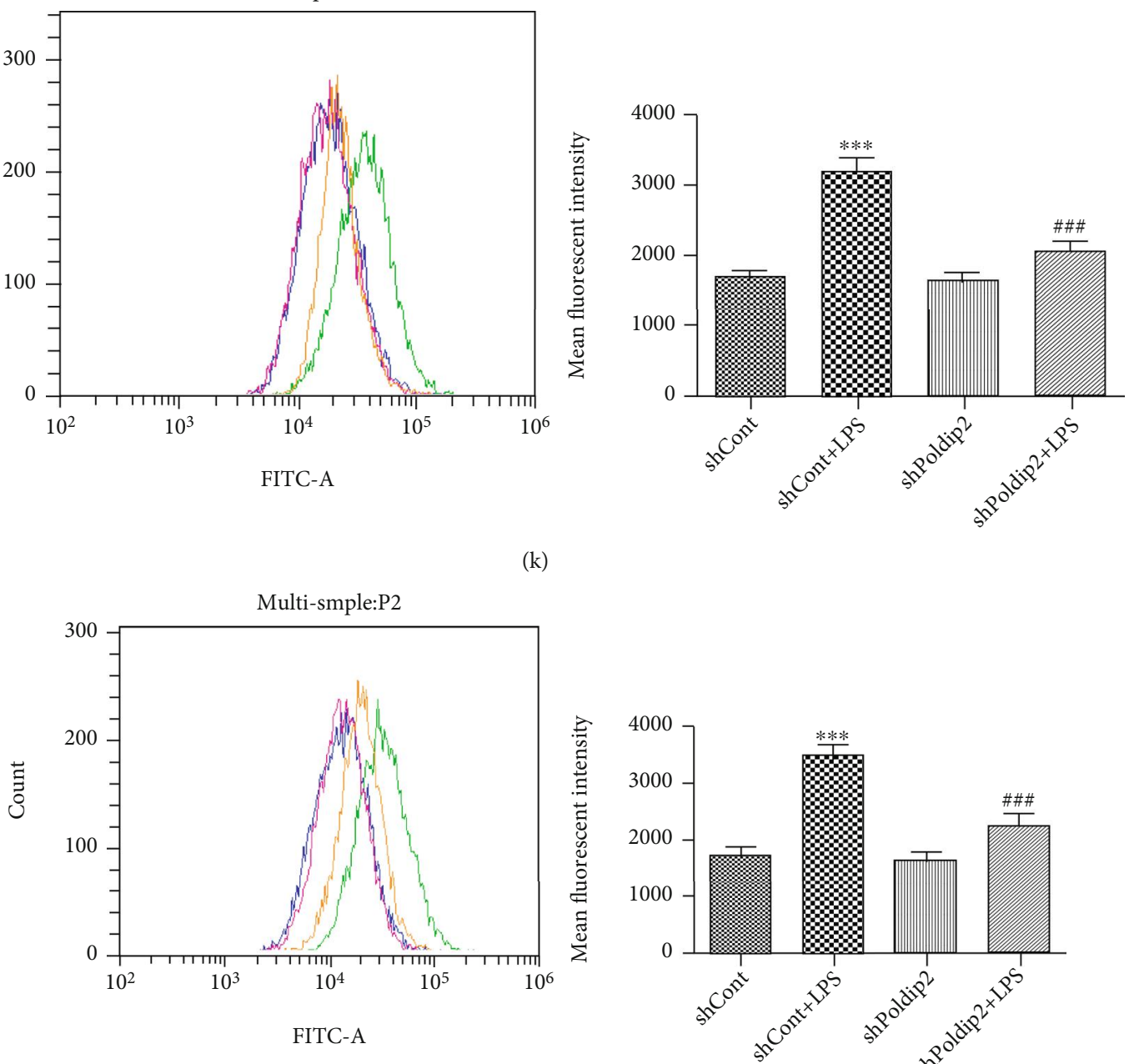

shCont

shPoldip2

shCont+LPS

$\square$ shPoldip2+LPS

(1)

Figure 5: Continued. 


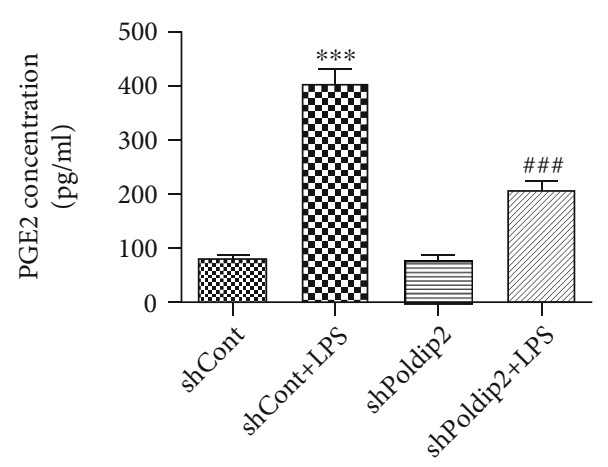

(m)

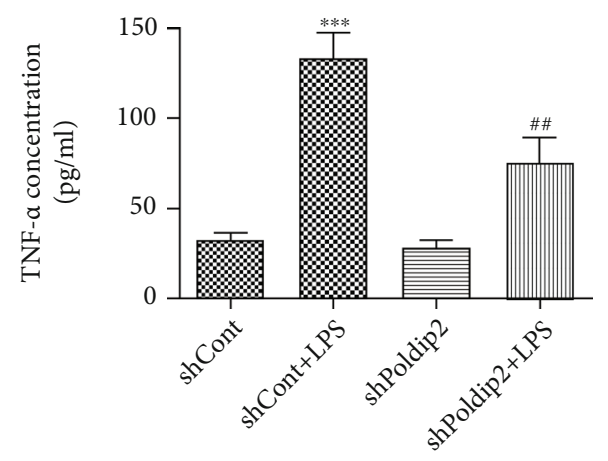

(o)

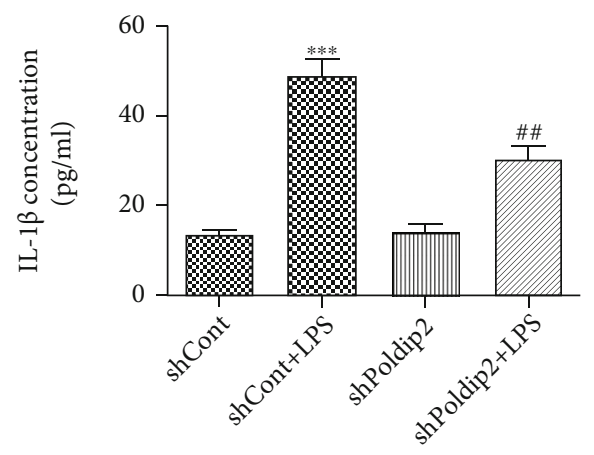

(q)

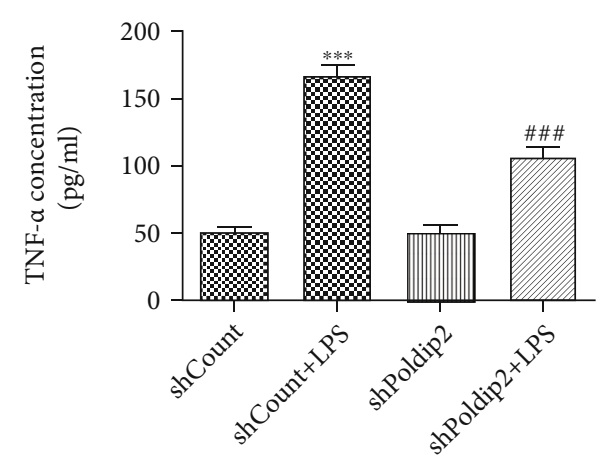

(n)

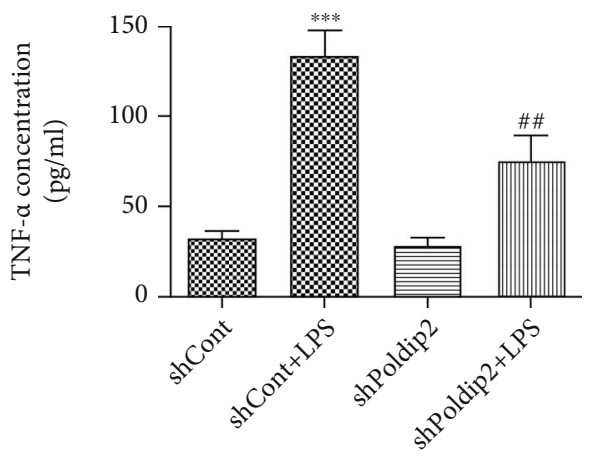

(p)

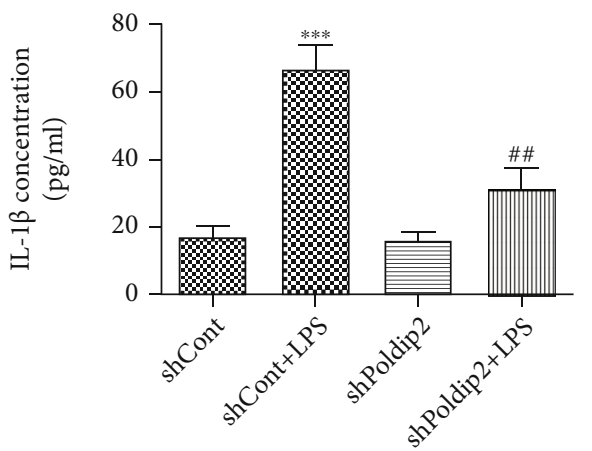

(r)

Figure 5: Downregulation of Poldip2 decreased LPS-induced oxidative stress and inflammation. (a, b) Confluent A549 and Beas-2B cells were transfected with the lentivirus downregulation vector for $72 \mathrm{~h}$, and the efficiency of Poldip 2 downregulation was verified by Western blotting and quantitatively analyzed. Following transfection, they were treated with LPS $(10 \mu \mathrm{g} / \mathrm{mL}$ for A549 cells and $1 \mu \mathrm{g} / \mathrm{mL}$ for Beas-2B cells) for $12 \mathrm{~h}$. (c, d) The protein levels of Nox4, HO-1, and COX-2 were detected by Western blotting and quantitatively analyzed. (e-g, i) The expression of Nox4 in the transfected cells was detected by immunofluorescence analysis and laser confocal microscope. The cells were stained with Nox4 (green) and counter stained with DAPI (blue) (magnification of 400x). (h, j) The NADPH enzymatic activity in cells was detected by a spectrophotometer. $(k, 1)$ The production of intracellular ROS was detected by flow cytometry. (m-r) The expression levels of PGE2, TNF- $\alpha$, and IL- $1 \beta$ in the supernatant were detected by ELISA. Bars are mean \pm SD of 3 independent experiments. ${ }^{* * *} P<0.001$ vs. shCont, ${ }^{* *} P<0.01$ vs. shCont, ${ }^{*} P<0.05$ vs. shCont, $\# \# \#<0.001$ vs. shCont + LPS, ${ }^{\# \#} P<0.01$ vs. shCont + LPS, and ${ }^{\#} P<0.05$ vs. shCont + LPS.

ARDS mouse model $[13,23]$. All these results suggested the possibility that coincident expression of Poldip2 and Nox4 was essential for the progression of ALI.

Previous data suggested that Poldip2 binds to Nox4 and showed a functional association in vascular smooth muscle [20]; in line with this, we found a correlation between Poldip2 and Nox4 in the regulation of LPS-induced oxidative stress and inflammation in lung epithelial cells. We further explored how Poldip2 and Nox4 interacted by using the
siRNA or upregulation of plasmid targeting Nox4. Our data suggested that Nox4 acted as the downstream of Poldip2 and was required for the effect of Poldip2 in response to LPS. consistent with our finding, Datla and his colleagues showed that Poldip2 controls Vascular Smooth Muscle Cell (VSMC) migration through regulating focal adhesion turnover and traction force production via activation of Nox4/RhoA/ FAK signaling [29]. However, as we know, the downstream targets of Nox4 implicated in the development of ALI have 


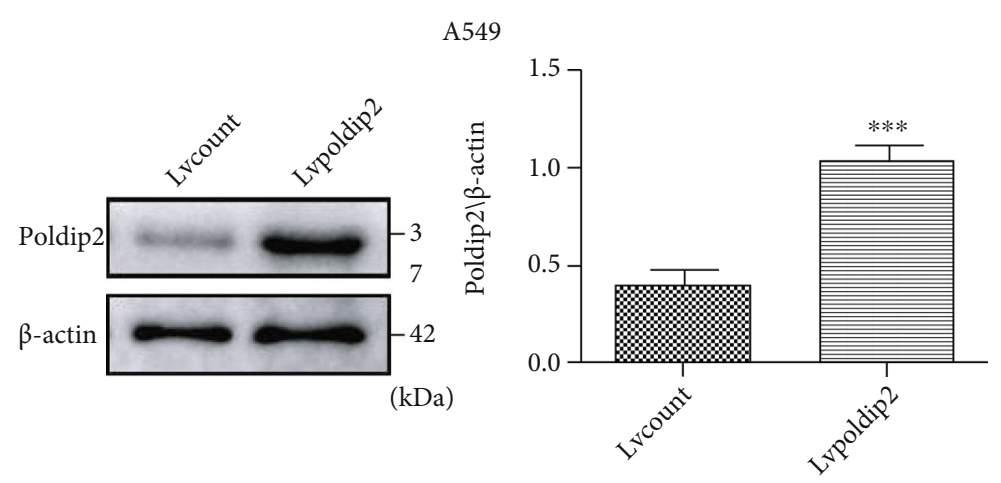

(a)

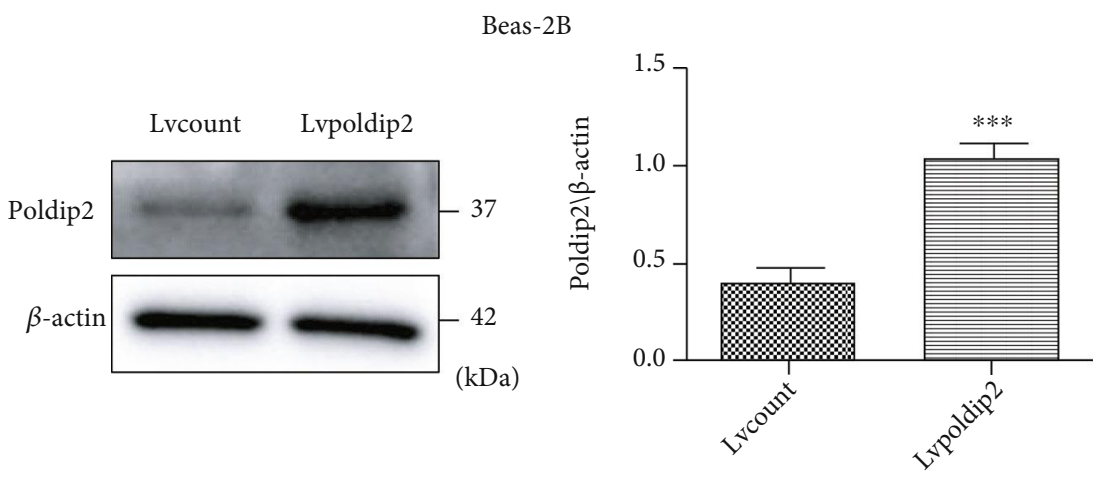

(b)
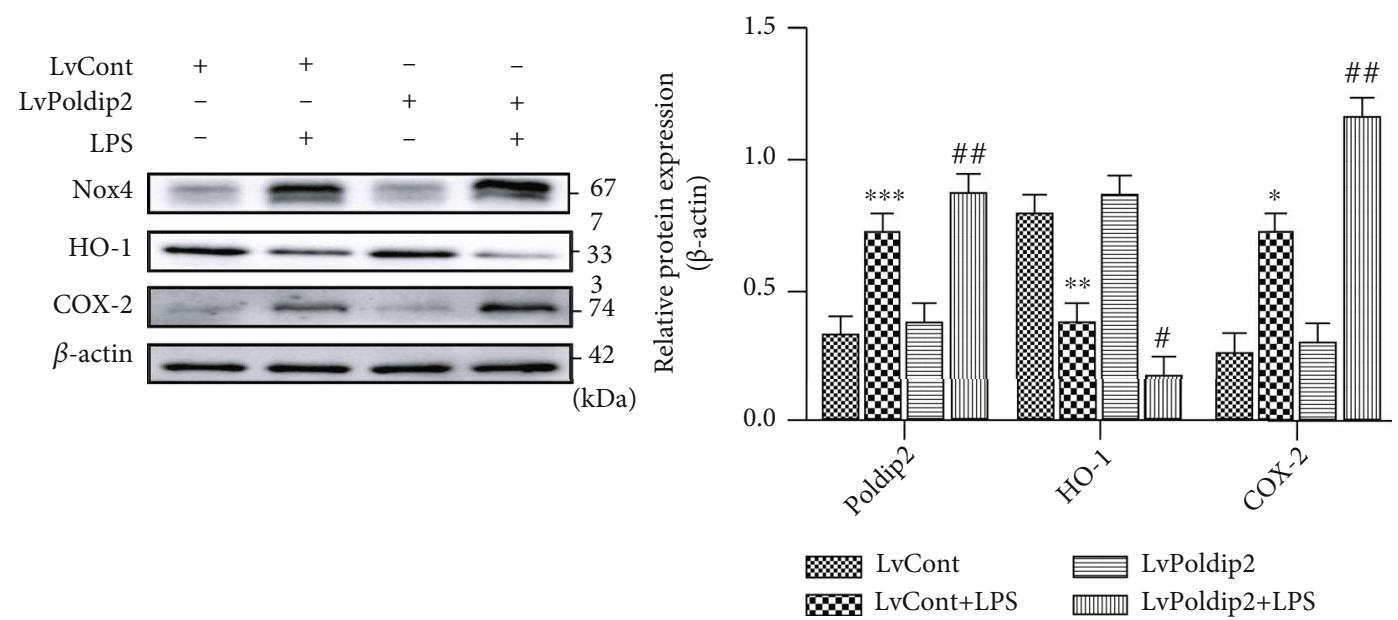

(c)

Figure 6: Continued. 

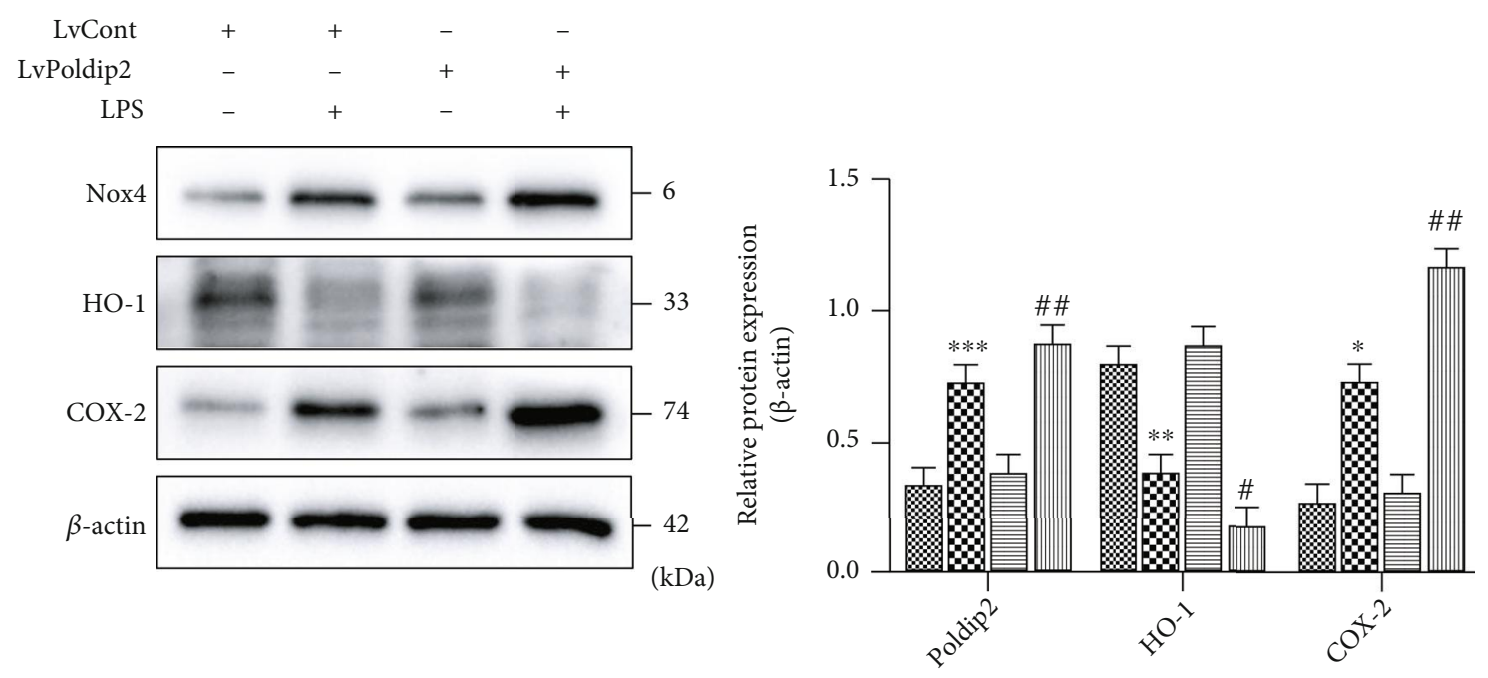

$\begin{array}{ll}\text { \%⿴囗大 LvCont } & \text { LvPoldip2 } \\ \text { \$W LvCont+LPS } & \text { Lveldip2+LPS }\end{array}$

(d)

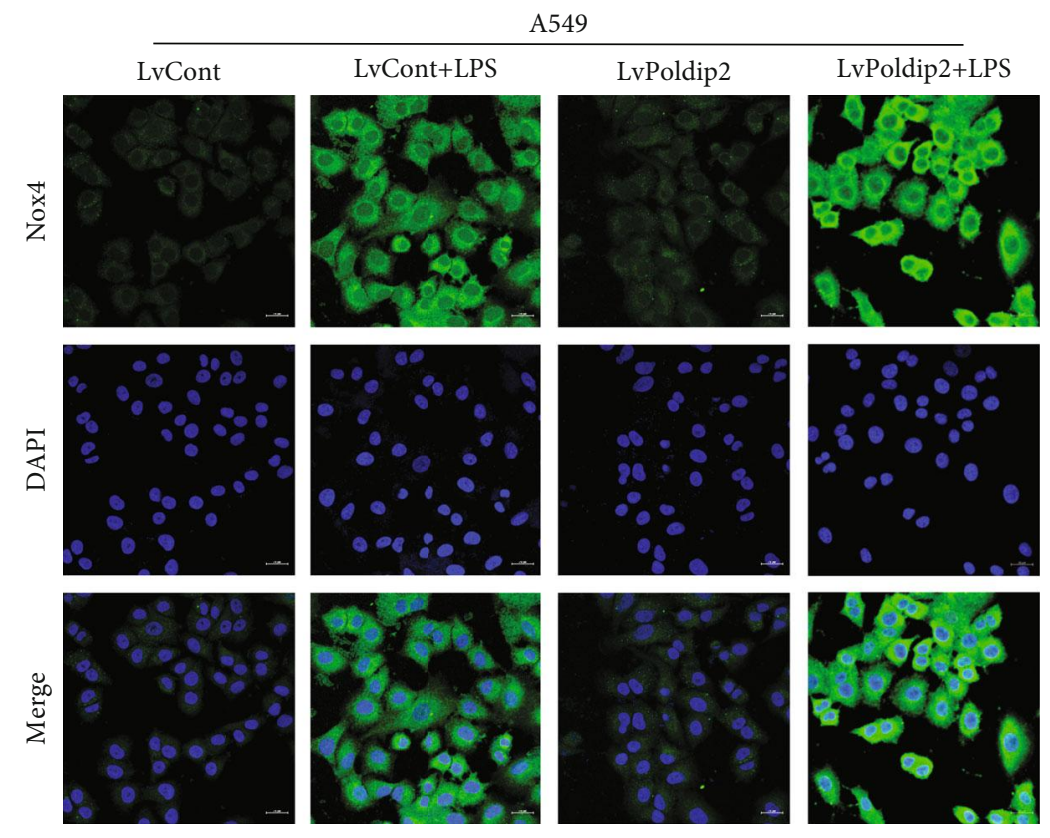

(e)

Figure 6: Continued. 


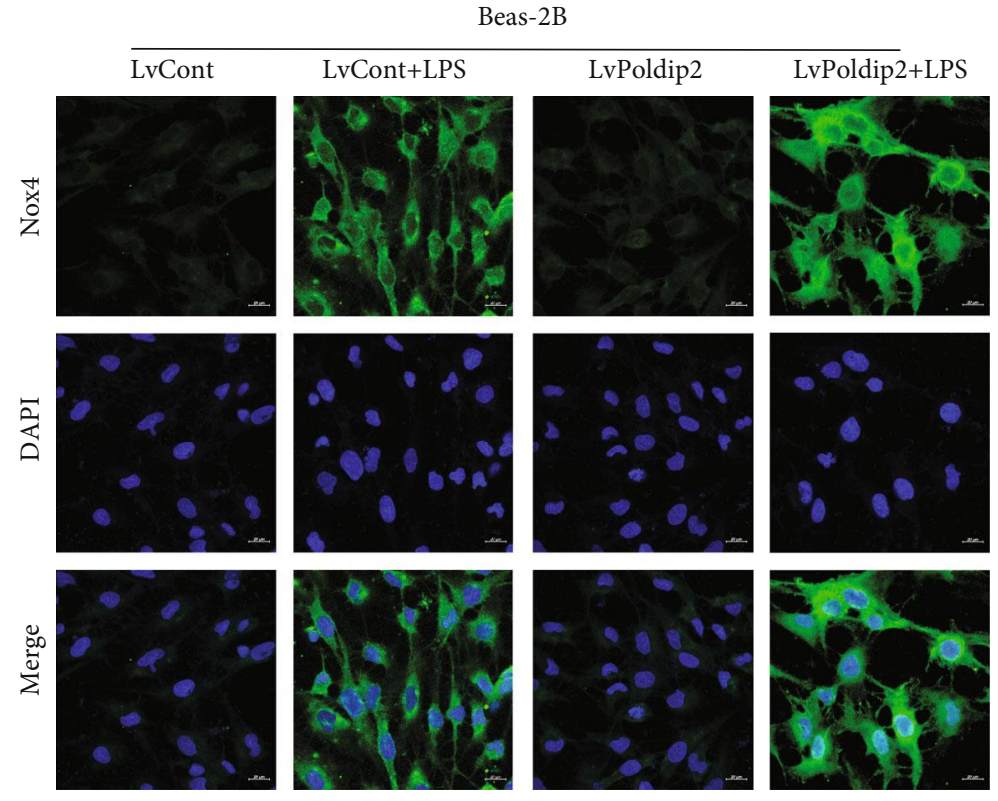

(f)

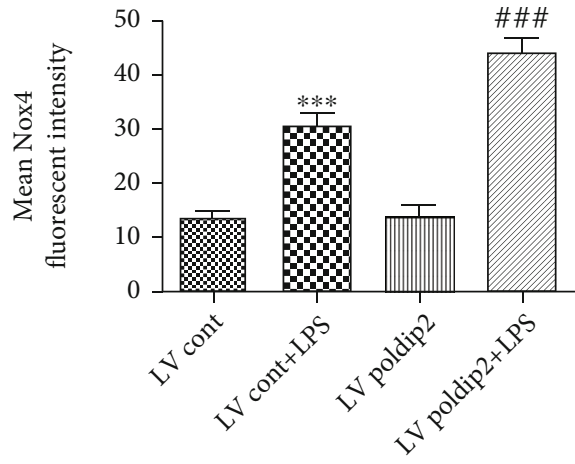

(g)

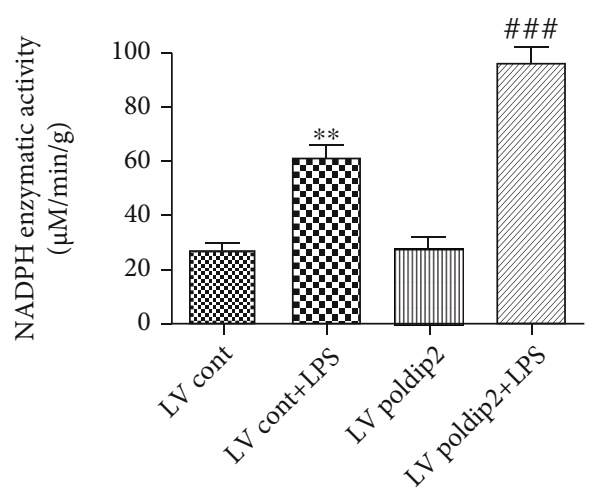

(h)

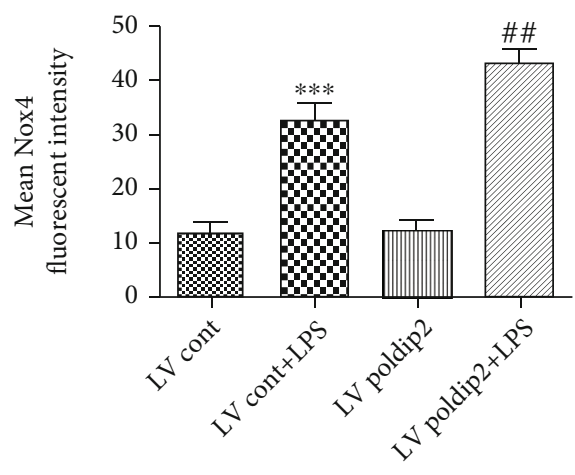

(i)

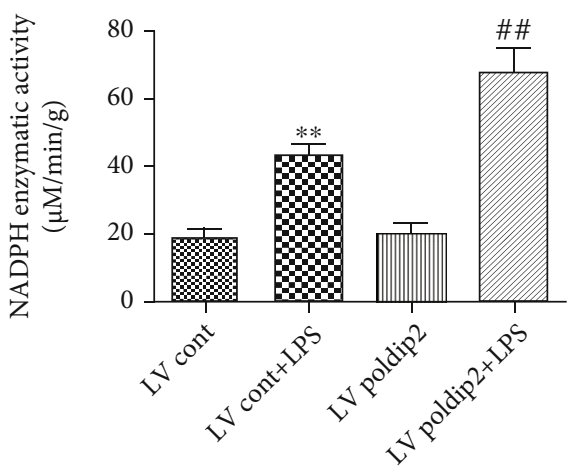

(j)

Figure 6: Continued. 

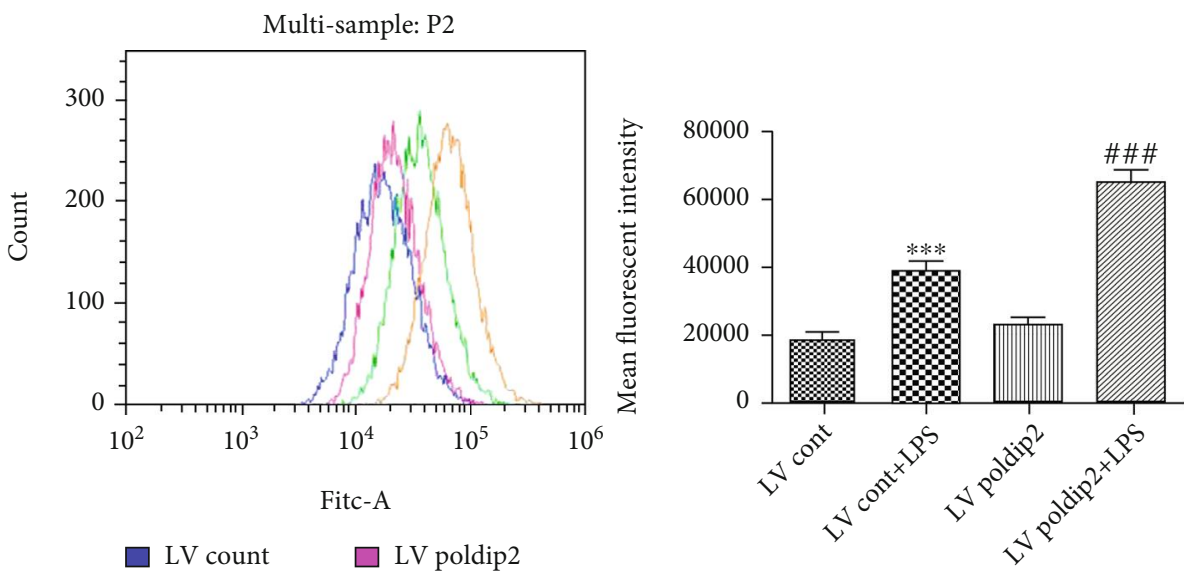

$\square$ LV count $\quad \square$ LV poldip2
$\square$ LV count+LPS $\square$ LV poldip2+LPS

(k)

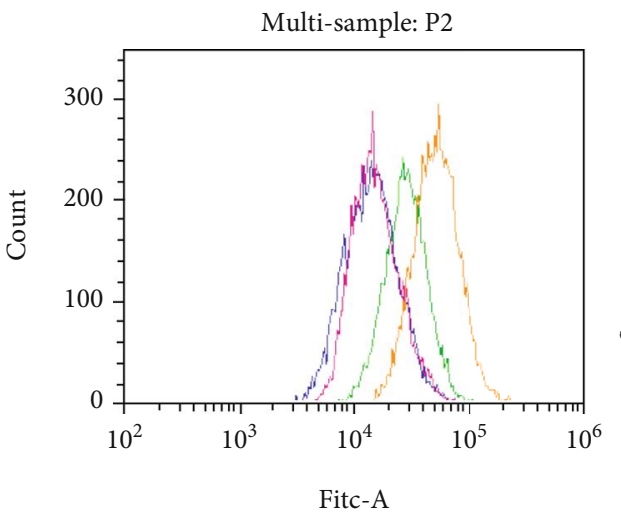

itc-A

$\begin{array}{ll}\square \text { LV count } & \square \text { LV poldip2 } \\ \square \text { LV count+LPS } & \square \text { LV poldip2+LPS }\end{array}$

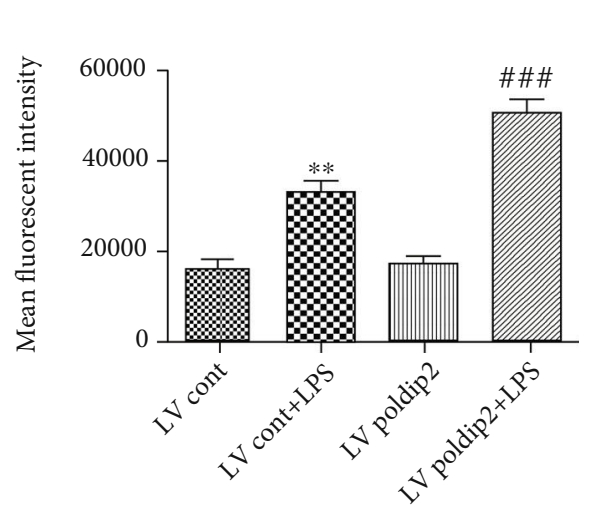

(l)

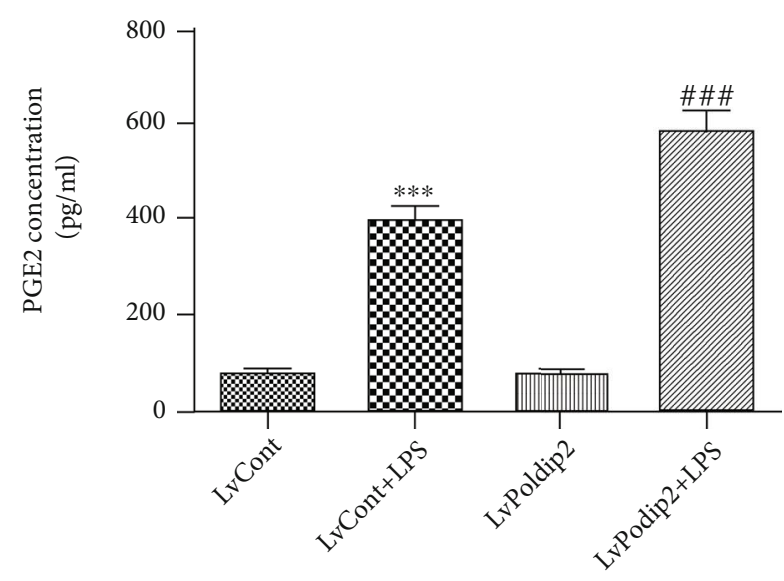

(m)

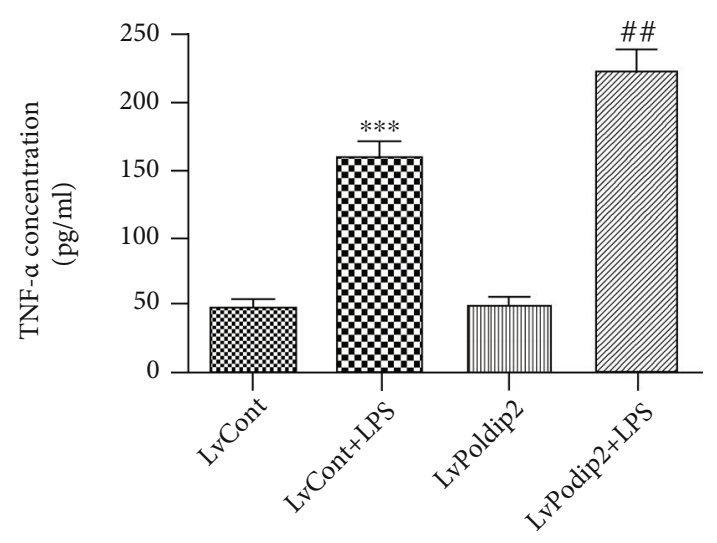

(n)

Figure 6: Continued. 


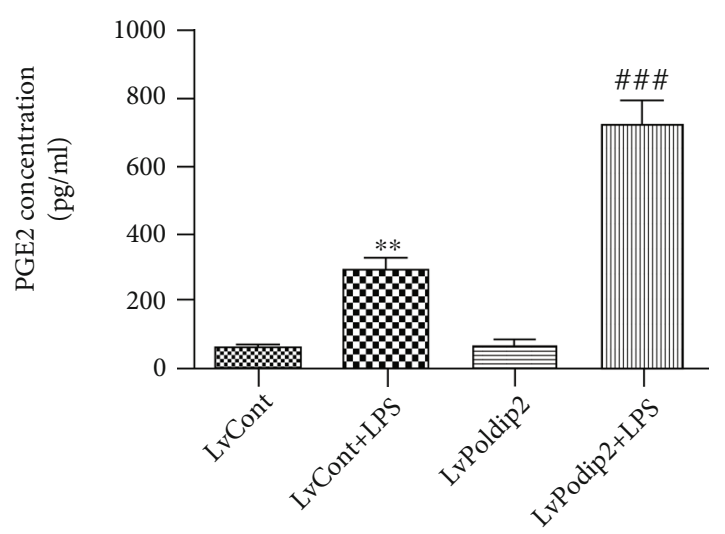

(o)

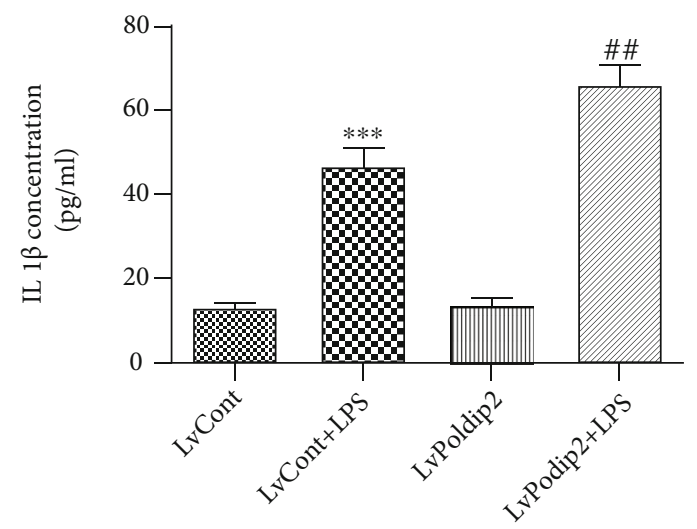

(q)

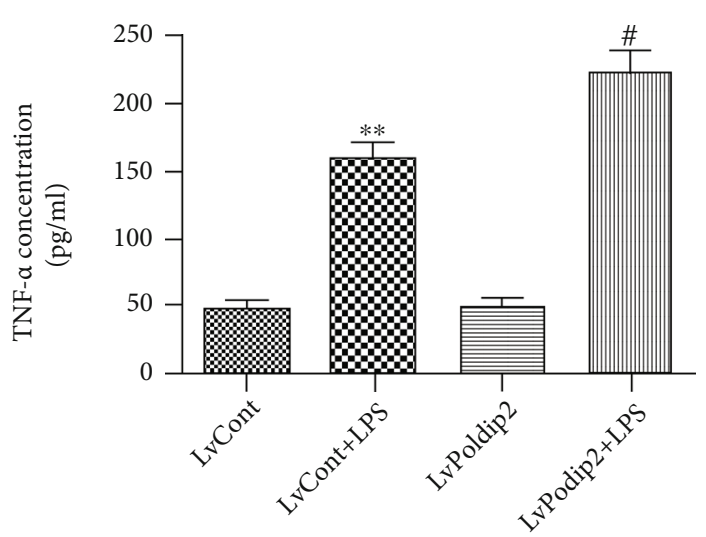

(p)

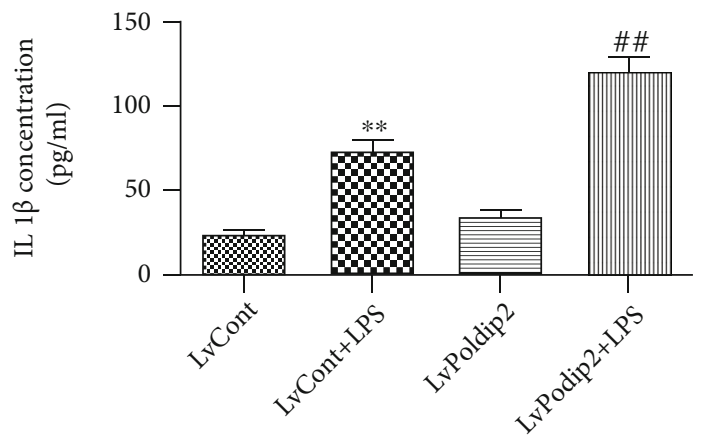

$(\mathrm{r})$

FIgURe 6: Upregulation of Poldip2 increased LPS-induced oxidative stress and inflammation. (a, b) Confluent A549 and Beas-2B cells were transfected with the lentivirus upregulation vector for $72 \mathrm{~h}$, and the efficiency of Poldip 2 upregulation was verified by Western blotting and quantitatively analyzed. Following transfection, they were treated with LPS ( $10 \mu \mathrm{g} / \mathrm{mL}$ for A549 cells and $1 \mu \mathrm{g} / \mathrm{mL}$ for Beas-2B cells) for $12 \mathrm{~h}$. (c, d) The protein levels of Nox4, HO-1, and COX-2 were detected by Western blotting and quantitatively analyzed. (e-g, i) The expression of Nox4 in the transfected cells was detected by immunofluorescence analysis and a laser confocal microscope. The cells were stained with Nox4 (green) and counter stained with DAPI (blue) (magnification of 400x). (h, j) The NADPH enzymatic activity in cells was detected by a spectrophotometer. $(k, l)$ The production of intracellular ROS was detected by flow cytometry. (m-r) The expression levels of PGE2, TNF- $\alpha$, and IL- $1 \beta$ in the supernatant were detected by ELISA. Bars are mean \pm SD of 3 independent experiments. ${ }^{* * *} P<0.001$ vs. LvCont, ${ }^{* *} P<0.01$ vs. LvCont, ${ }^{*} P<0.05$ vs. LvCont, ${ }^{\# \# ~} P<0.001$ vs. LvCont + LPS, ${ }^{\#} P<0.01$ vs. LvCont + LPS, and ${ }^{\#} P<0.05$ vs. LvCont + LPS.

not been well understood. HO-1, an inducible antioxidant enzyme, is considered to be the main protein protecting against LPS-induced ALI [30]. Meanwhile, COX-2, a proinflammatory mediator, is highly expressed in alveolar epithelial cells and its expression contributes to the poor outcome of ALI [31]. It has been reported that LPS-induced HO-1 and COX-2 expression was significantly attenuated by NADPH oxidase inhibitors [32, 33]. Consistent with these studies, we found that downregulation of Nox4 using siRNA significantly suppressed COX-2 expression but enhanced HO-1 expression under LPS stimulation.

The NADPH oxidase enzyme is an enzyme complex system, which composes of transmembrane protein catalytic subunits and cytosolic regulatory subunits; it becomes active after regulatory subunits translocate to the plasma membrane and interact with catalytic subunits to form the functional enzyme [34]. However, the mechanism of Nox4 activation in response to LPS has not been fully understood.
As described earlier, Poldip2 as acted an upstream regulator of Nox4 and interacted with Nox4 under LPS stimulation. Importantly, after lentivirus-mediated Poldip2 downregulation and being challenged by LPS in lung epithelial cells, we found that the expression of Nox4, enzymatic activity of NADPH oxidases, and production of ROS were significantly inhibited, which were accompanied by decreased COX-2 and increased HO-1 expression, indicating that Poldip2 may function similarly to other NADPH oxidase cytosolic regulatory subunits. Indeed, upregulation of Poldip2 significantly increased oxidative stress and inflammation in LPS-stimulated lung epithelial cells. Consistent with our findings, a previous study also supported the active effects of Poldip 2 on Nox 4 expression. For example, upregulation of Poldip2 using adenovirus caused a significant increase in Nox4 enzymatic activity and basal ROS production, whereas Poldip2 downregulation by siRNA significantly decreases ROS production in VSMCs [20]. It is therefore possible that 


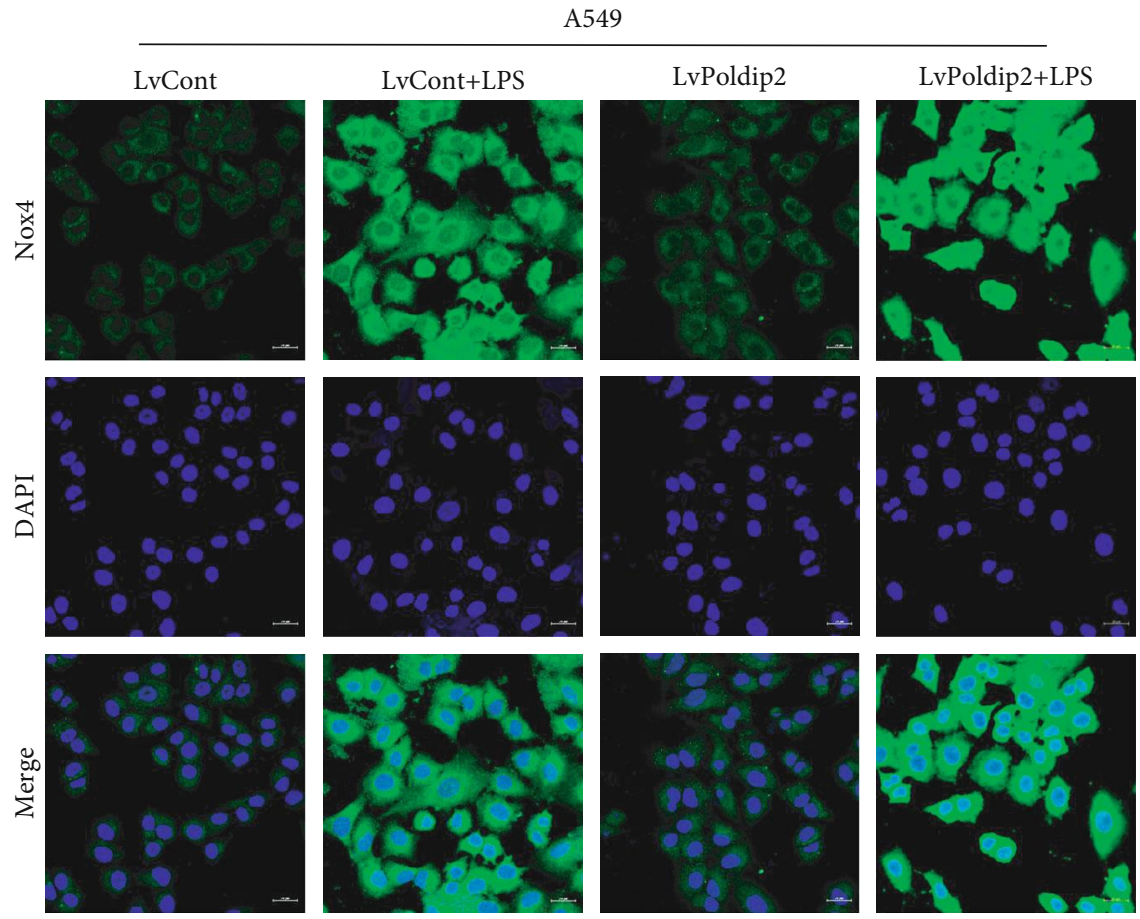

(a)
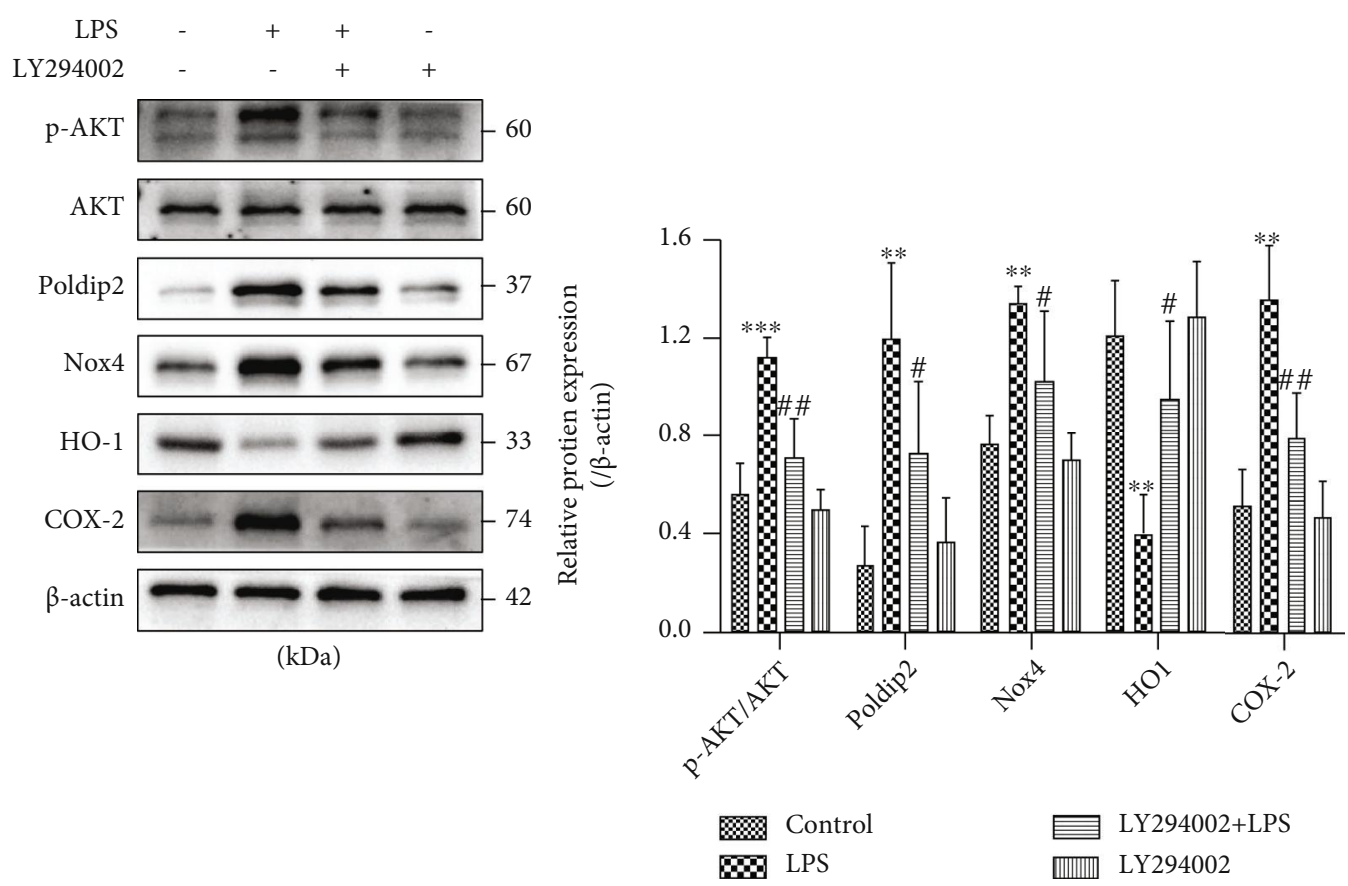

(b)

FIgUre 7: Continued. 

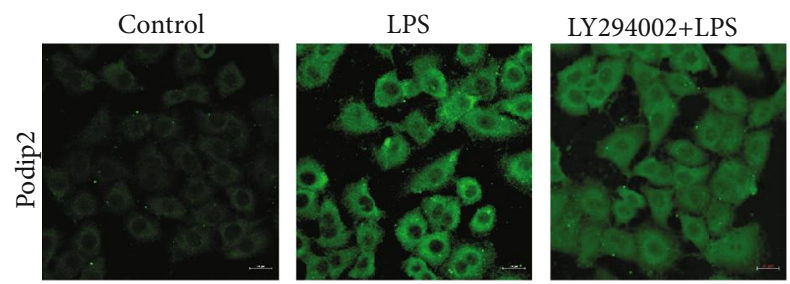

LY294002
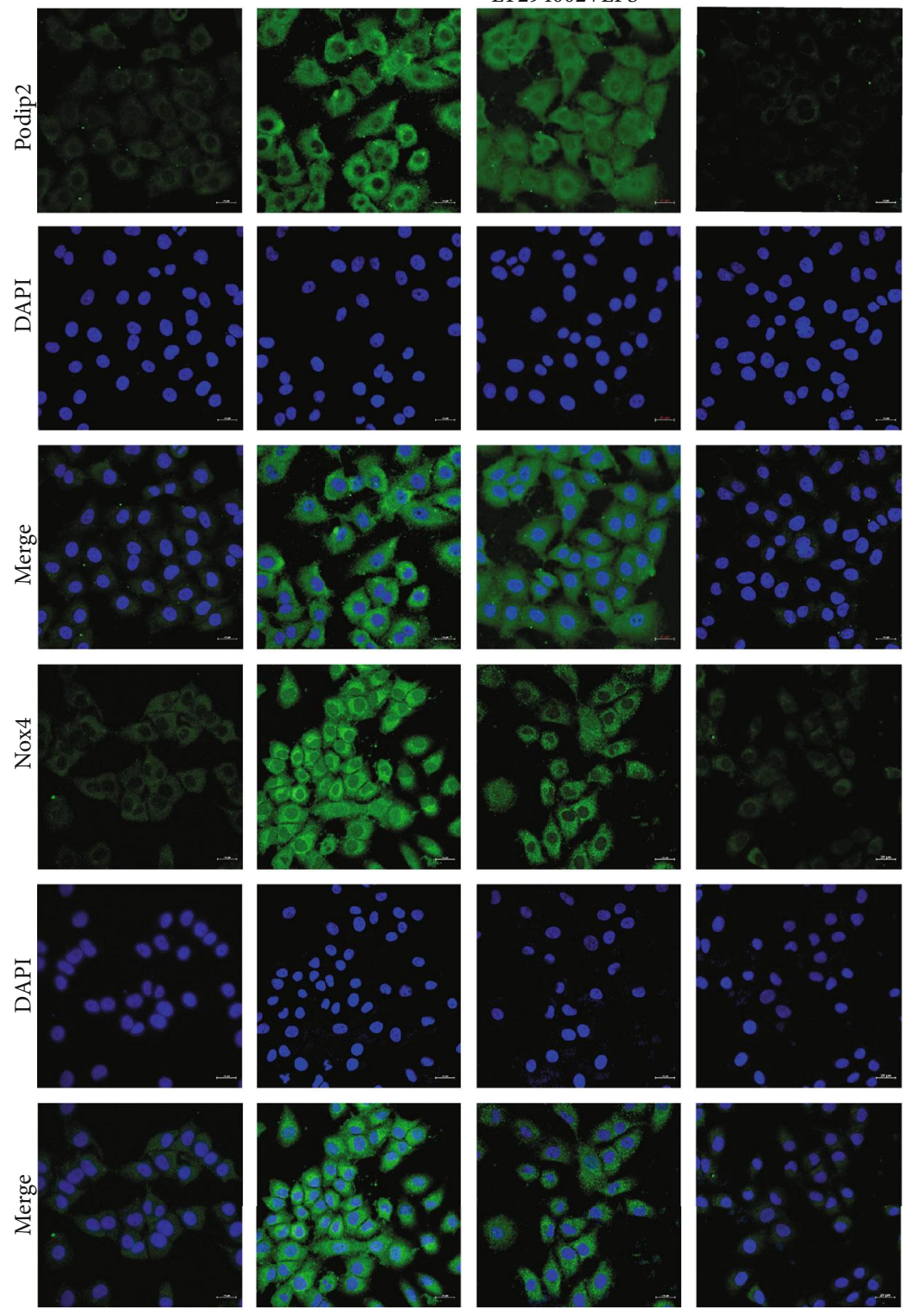

(c)

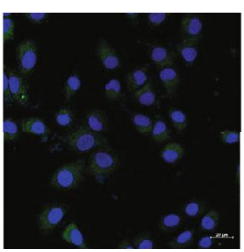

Figure 7: Continued. 


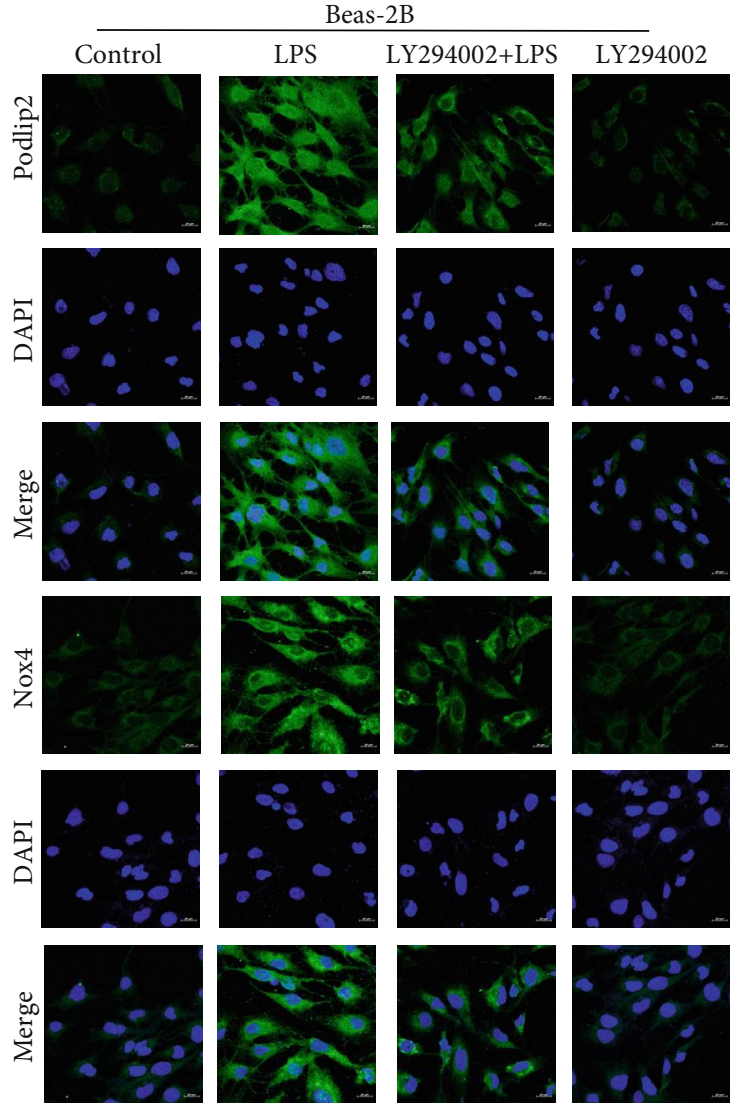

(d)

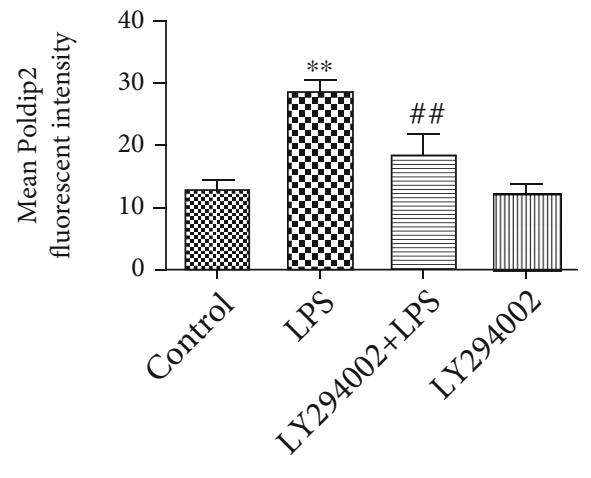

(g)

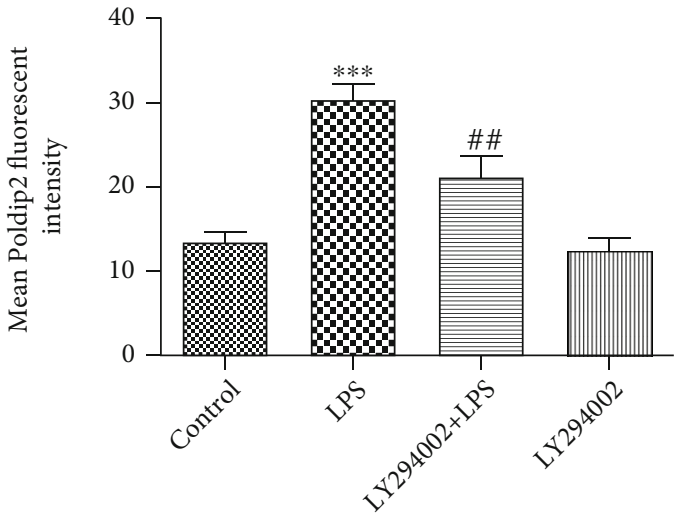

(e)

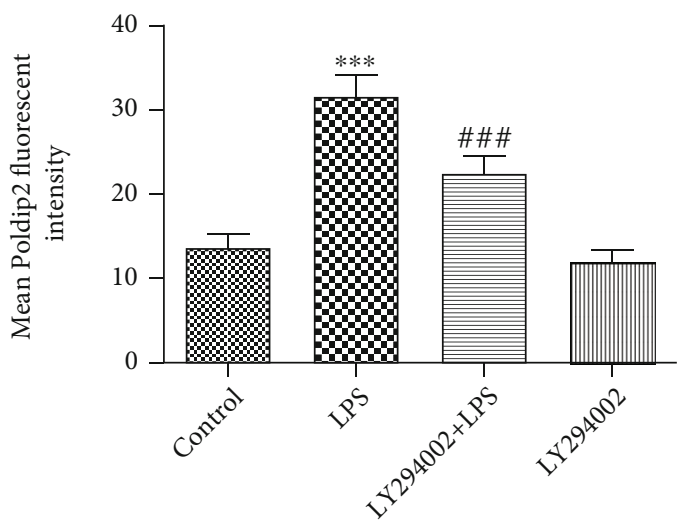

$(\mathrm{f})$

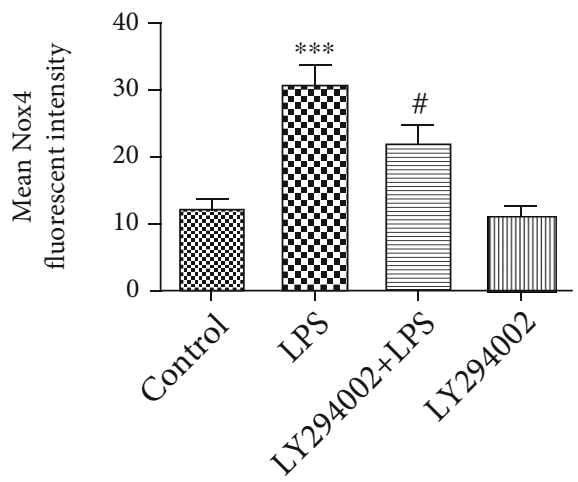

(h)

Figure 7: Effects of PI3K-AKT signaling on the activation of the Poldip2/Nox4-mediated pathway. Confluent A549 and Beas-2B cells were pretreated with $10 \mu \mathrm{mol} / \mathrm{L}$ LY294002 for $1 \mathrm{~h}$ followed by postincubation with LPS ( $10 \mu \mathrm{g} / \mathrm{mL}$ for A549 cells and $1 \mu \mathrm{g} / \mathrm{mL}$ for Beas-2B cells) for $12 \mathrm{~h}$. (a, b) The protein levels of p-AKT, AKT, Poldip2, Nox4, HO-1, and COX-2 were detected by Western blotting and quantitatively analyzed. (c-h) The expression of Poldip 2 and Nox4 in cells was detected by immunofluorescence analysis and a laser confocal microscope. The cells were stained with Poldip2 (green), Nox4 (green), and counter-stained with DAPI (blue) (magnification of 400x). Bars are mean \pm SD of 3 independent experiments. ${ }^{* * *} P<0.001$ vs. control, ${ }^{* *} P<0.01$ vs. control, ${ }^{*} P<0.05$ vs. control, ${ }^{\# \# \# ~} P<0.001$ vs. LPS, $\#$ \# $P<0.01$ vs. LPS, and ${ }^{\#} P<0.05$ vs. LPS.

inhibition of Poldip2 expression may represent a novel mechanism for limiting oxidative stress and inflammation in LPS-induced ALI.

In addition, PI3K-AKT signaling was considered as a critical signaling pathway in mammalian cells that regulates cell growth, proliferation, metabolism, and motility [35]. Increasing evidence has suggested that PI3K-AKT signaling is a major pathway involved in the development of ALI
$[36,37]$. In our study, we explored that pretreatment with LY294002 significantly suppressed LPS-induced increase in Poldip2, Nox4, and COX-2 and decrease in HO-1 in lung epithelial cells, indicating that PI3K-AKT signaling acts as an upstream regulator of Poldip2. We speculated that PI3K-AKT signaling may be involved in regulating Poldip2 expression and eventually affected the activity of Nox4. However, the precise mechanism involved in PI3K-AKT 
signaling that regulates Poldip2 expression is unclear and requires further investigation.

Our findings suggest that Poldip2 is involved in oxidative stress and inflammation through interacting with Nox4 and is regulated by the PI3K-AKT signaling, which may contribute to better understanding of the plausible mechanism of acute lung injury.

\section{Data Availability}

The data used to support the findings of this study are available from the corresponding author upon request.

\section{Conflicts of Interest}

The authors declare that there are no conflicts of interest.

\section{Authors' Contributions}

Conceptualization was done by Guanghe Fei and Yueguo Wang; formal analysis was done by Yueguo Wang, Youhui $\mathrm{Tu}, \mathrm{Xu} \mathrm{Wu}$, and Wenying Zhang; the investigation was done by Yueguo Wang; the methodology was done by Yueguo Wang, and Zhenxing Ding; project administration was done by Huimei $\mathrm{Wu}$ and Guanghe Fei; writing of the original draft was done Yueguo Wang and Zhenxing Ding; reviewing \& editing of the writing were done by Yueguo Wang, Shuang Ji, Jilong Shen, Li Zhang, Huimei Wu, and Guanghe Fei. Yueguo Wang and Zhenxing Ding contributed equally to this work.

\section{Acknowledgments}

We would like to sincerely thank Dandan Zang and Fang Ma of the Center for Scientific Research of Anhui Medical University for the valuable help in our experiment. This work was supported by the National Natural Science Foundation of China $(81870036,81770032)$ and Development Plan of Anhui Province (1804h08020237).

\section{References}

[1] S. Guo, K. F. Jiang, H. C. Wu et al., "Magnoflorine ameliorates lipopolysaccharide-induced acute lung injury via suppressing NF- $\kappa \mathrm{B}$ and MAPK activation," Frontiers in Pharmacology, vol. 9, no. 1, p. 982, 2018.

[2] H. T. Hsu, Y. T. Tseng, Y. Y. Hsu, K. I. Cheng, S. H. Chou, and Y. C. Lo, "Propofol attenuates lipopolysaccharide-induced reactive oxygen species production through activation of $\mathrm{Nrf2/GSH}$ and suppression of NADPH oxidase in human alveolar epithelial cells," Inflammation, vol. 38, no. 1, pp. 415-423, 2015.

[3] D. Zhang, J. Zhou, L. C. Ye et al., "Autophagy maintains the integrity of endothelial barrier in LPS-induced lung injury," Journal of Cellular Physiology, vol. 233, no. 1, pp. 688-698, 2018.

[4] C. W. Chow, M. T. Herrera Abreu, T. Suzuki, and G. P. Downey, "Oxidative stress and acute lung injury," American journal of respiratory cell and molecular biology, vol. 29, no. 4, pp. 427-431, 2003.
[5] C. Y. Chen, Y. F. Tsai, W. J. Huang, S. H. Chang, and T. L. Hwang, "Propofol inhibits endogenous formyl peptideinduced neutrophil activation and alleviates lung injury," Journal of Free Radicals in Biology \& Medicine, vol. 129, pp. 372$382,2018$.

[6] R. K. Thimmulappa, H. Lee, T. Rangasamy et al., "Nrf2 is a critical regulator of the innate immune response and survival during experimental sepsis," The Journal of Clinical Investigation, vol. 116, no. 4, pp. 984-995, 2006.

[7] J. M. Li, L. M. Fan, M. R. Christie, and A. M. Shah, “Acute tumor necrosis factor alpha signaling via NADPH oxidase in microvascular endothelial cells: role of $\mathrm{p} 47$ phox phosphorylation and binding to TRAF4," Molecular and Cellular Biology, vol. 25, no. 6, pp. 2320-2330, 2005.

[8] Y. Tada and J. I. Suzuki, "Oxidative stress and myocarditis," Current Pharmaceutical Design, vol. 22, no. 4, pp. 450-471, 2016.

[9] S. Carnesecchi, C. Deffert, Y. Donati et al., “A key role for Nox4 in epithelial cell death during development of lung fibrosis," Antioxidants \& Redox Signaling, vol. 15, no. 3, pp. 607619, 2011.

[10] R. L. Cho, C. C. Yang, I. T. Lee et al., "Lipopolysaccharide induces ICAM-1 expression via a c-Src/NADPH oxidase/ ROS-dependent NF- $\kappa$ B pathway in human pulmonary alveolar epithelial cells," American Journal of Physiology. Lung Cellular and Molecular Physiology, vol. 310, no. 7, pp. L639-L657, 2016.

[11] S. Palumbo, Y. J. Shin, K. Ahmad et al., "Dysregulated Nox4 ubiquitination contributes to redox imbalance and agerelated severity of acute lung injury," American Journal of Physiology. Lung Cellular and Molecular Physiology, vol. 312, no. 3, pp. L297-L308, 2017.

[12] L. Liu, E. M. Rodriguez-Belmonte, N. Mazloum, B. Xie, and M. Y. W. T. Lee, "Identification of a Novel Protein, PDIP38, That Interacts with the p50 Subunit of DNA Polymerase $\delta$ and Proliferating Cell Nuclear Antigen," The Journal of Biological Chemistry, vol. 278, no. 12, pp. 10041-10047, 2003.

[13] S. J. Forrester, Q. Xu, D. S. Kikuchi et al., "Poldip2 deficiency protects against lung edema and vascular inflammation in a model of acute respiratory distress syndrome," Clinical Science, vol. 133, no. 2, pp. 321-334, 2019.

[14] A. Wong, S. Zhang, D. Mordue et al., "PDIP38 is translocated to the spliceosomes/nuclear speckles in response to UVinduced DNA damage and is required for UV-induced alternative splicing of MDM2," Cell Cycle, vol. 12, no. 19, pp. 3184-3193, 2013.

[15] X. Cheng, T. Kanki, A. Fukuoh et al., "PDIP38 Associates with Proteins Constituting the Mitochondrial DNA Nucleoid," Journal of Biochemistry, vol. 138, no. 6, pp. 673-678, 2005.

[16] N. Arakaki, T. Nishihama, A. Kohda et al., "Regulation of mitochondrial morphology and cell survival by mitogenin I and mitochondrial single-stranded DNA binding protein," Biochimica et Biophysica Acta (BBA)-General Subjects, vol. 1760, no. 9, pp. 1364-1372, 2006.

[17] M. Fujii, A. Amanso, T. B. Abrahão, B. Lassègue, and K. K. Griendling, "Polymerase delta-interacting protein 2 regulates collagen accumulation via activation of the Akt/mTOR pathway in vascular smooth muscle cells," Journal of Molecular and Cellular Cardiology, vol. 92, pp. 21-29, 2016.

[18] A. M. Amanso, B. Lassègue, G. Joseph et al., "Polymerase $\delta$ Interacting protein 2 promotes postischemic neovascularization 
of the mouse hindlimb," Arteriosclerosis, Thrombosis, and Vascular Biology, vol. 34, no. 7, pp. 1548-1555, 2014.

[19] D. I. Brown, B. Lassègue, M. Lee et al., "Poldip2 knockout results in perinatal lethality, reduced cellular growth and increased autophagy of mouse embryonic fibroblasts," PLoS One, vol. 9, no. 5, article e96657, 2014.

[20] A. N. Lyle, N. N. Deshpande, Y. Taniyama et al., "Poldip2, a novel regulator of Nox4 and cytoskeletal integrity in vascular smooth muscle Cells," Circulation Research, vol. 105, no. 3, pp. 249-259, 2009.

[21] H. S. Huang, Z. M. Liu, P. C. Chen, H. Y. Tseng, and B. W. Yeh, "TG-interacting factor-induced superoxide production from NADPH oxidase contributes to the migration/invasion of urothelial carcinoma," Free Radical Biology \& Medicine, vol. 53, no. 4, pp. 769-778, 2012.

[22] I. T. Lee and C. M. Yang, "Role of NADPH oxidase/ROS in pro-inflammatory mediators-induced airway and pulmonary diseases," Biochemical Pharmacology, vol. 84, no. 5, pp. 581590, 2012.

[23] J. Y. Jiang, K. Huang, S. Q. Xu, J. G. N. Garcia, C. Wang, and H. Cai, "Targeting NOX4 alleviates sepsis-induced acute lung injury via attenuation of redox-sensitive activation of CaMKII/ERK1/2/MLCK and endothelial cell barrier dysfunction," Redox Biology, vol. 36, article 101638, 2020.

[24] D. D. Chai, L. Zhang, S. W. Xi, Y. Y. Cheng, H. Jiang, and R. Hu, "Nrf2 activation induced by Sirt1 ameliorates acute lung injury after intestinal ischemia/reperfusion through NOX4-mediated gene regulation," Cellular Physiology and Biochemistry, vol. 46, no. 2, pp. 781-792, 2018.

[25] W. Li, Z. N. Cai, S. Mehmood et al., "Polysaccharide FMP-1 from Morchella esculenta attenuates cellular oxidative damage in human alveolar epithelial A549 cells through PI3K/AKT/ Nrf2/HO-1 pathway," International Journal of Biological Macromolecules, vol. 120, pp. 865-875, 2018.

[26] M. C. Zeng, W. H. Sang, S. Chen et al., "4-PBA inhibits LPSinduced inflammation through regulating ER stress and autophagy in acute lung injury models," Toxicology Letters, vol. 271, pp. 26-37, 2017.

[27] H. M. Wu, Z. F. Jiang, P. S. Ding, L. J. Shao, and R. Y. Liu, "Hypoxia-induced autophagy mediates cisplatin resistance in lung cancer cells," Scientific Reports, vol. 5, no. 1, pp. 1-15, 2015.

[28] D. S. Kikuchi, A. C. P. Campos, H. Qu et al., "Poldip2 mediates blood-brain barrier disruption in a model of sepsis-associated encephalopathy," Journal of Neuroinflammation, vol. 16, no. 1, pp. 1-12, 2019.

[29] S. R. Datla, D. J. McGrail, S. Vukelic et al., "Poldip2 controls vascular smooth muscle cell migration by regulating focal adhesion turnover and force polarization," American Journal of Physiology. Heart and Circulatory Physiology, vol. 307, no. 7, pp. H945-H957, 2014.

[30] X. X. Chen, S. S. Wu, L. Tang et al., "Mesenchymal stem cells overexpressing heme oxygenase-1 ameliorate lipopolysaccharide- induced acute lung injury in rats," Journal of Cellular Physiology, vol. 234, no. 5, pp. 7301-7319, 2019.

[31] J. Cheng, R. T. Dackor, J. A. Bradbury et al., "Contribution of alveolar type II cell-derived cyclooxygenase-2 to basal airway function, lung inflammation, and lung fibrosis," The FASEB Journal, vol. 30, no. 1, pp. 160-173, 2016.

[32] R. L. Cho, C. C. Yang, H. C. Tseng, L. D. Hsiao, C. C. Lin, and C. M. Yang, "Haem oxygenase-1 up-regulation by rosiglita- zone via ROS-dependent Nrf2-antioxidant response elements axis or PPAR $\gamma$ attenuates LPS-mediated lung inflammation," British Journal of Pharmacology, vol. 175, no. 20, pp. 39283946, 2018.

[33] M. H. Tsai, Z. C. Lin, C. J. Liang, F. L. Yen, Y. C. Chiang, and C. W. Lee, "Eupafolin inhibits PGE2 production and COX2 expression in LPS-stimulated human dermal fibroblasts by blocking JNK/AP-1 and Nox2/p47 phox pathway," Toxicology and Applied Pharmacology, vol. 279, no. 2, pp. 240-251, 2014.

[34] S. A. Belambri, L. Rolas, H. Raad, M. Hurtado-Nedelec, P. M. C. Dang, and J. el-Benna, "NADPH oxidase activation in neutrophils: role of the phosphorylation of its subunits," European Journal of Clinical Investigation, vol. 48, article e12951, 2018.

[35] M. Jafari, E. Ghadami, T. Dadkhah, and H. Akhavan-Niaki, "PI3k/AKT signaling pathway: erythropoiesis and beyond," Journal of Cellular Physiology, vol. 234, no. 3, pp. 2373-2385, 2019.

[36] L. Meng, L. Y. Li, S. Lu et al., "The protective effect of dexmedetomidine on LPS-induced acute lung injury through the HMGB1-mediated TLR4/NF- $\kappa$ B and PI3K/Akt/mTOR pathways," Molecular Immunology, vol. 94, pp. 7-17, 2018.

[37] Y. E. Liu, C. C. Tong, Y. Tang et al., "Tanshinone IIA alleviates blast-induced inflammation, oxidative stress and apoptosis in mice partly by inhibiting the $\mathrm{PI} 3 \mathrm{~K} / \mathrm{Akt} / \mathrm{FoxO} 1$ signaling pathway," Free Radical Biology \& Medicine, vol. 152, pp. 52-60, 2020. 